\title{
La separación conyugal en los Censos y en las Encuestas de Demografía y Salud en Colombia, 1951-2015*
}

\author{
The marital separation in the Census and in the \\ Demography and Health Surveys in Colombia, 1951-2015
}

\section{Fernando Ruiz-Vallejo ${ }^{1}$}

Investigador postdoctoral, Universidad Pompeu Fabra, Barcelona, España Integrante del Grupo de Investigación de Profamilia, Bogotá, Colombia

fernando.ruizv@upf.edu

https://orcid.org/0000-0003-1121-2562

Recibido: 09-05-19

Aprobado: 27-08-19

\footnotetext{
El presente artículo hace parte de la tesis del autor, con la cual obtuvo el título de Doctor en Demografía por el Centro de Estudios Demográficos (CED) de la Universidad Autónoma de Barcelona, bajo la dirección del Dr. Albert Esteve y la Dra. Montserrat Solsona. Para el desarrollo de la investigación el autor contó con una beca del Departamento Administrativo de Ciencia, Tecnología e Innovación, COLCIENCIAS (Convocatoria 617 de 2013).

1 Doctor en demografía.
} 


\section{Resumen}

El presente artículo tiene por objetivos medir la separación conyugal en Colombia para el periodo 1951-2015, y ofrecer una estimación corregida de la presencia de dicho fenómeno, a nivel municipal, a partir del Censo de 2005. Se aplican técnicas directas e indirectas para el cálculo del porcentaje de mujeres de 30 a 34 años que se encontraban separadas o divorciadas y, también, para aquellas que alguna vez habían experimentado dicho evento, sin importar su situación conyugal actual. Las fuentes empleadas fueron los Censos de población de 1951 a 2005 y las Encuestas Nacionales de Demografía y Salud para el periodo 1986-2015. Los resultados indican que, contrario al subregistro del Censo, la separación ha venido en aumento desde 1986 hasta llegar a un nivel de $34 \%$ en 2015. Sin embargo, existen variaciones territoriales importantes, siendo las regiones del Caribe, la Pacífica y la Amazonía/Orinoquía los lugares con los mayores niveles.

Palabras clave: divorcio; separación; estado civil; disolución de la familia.

\section{Abstract}

The purpose of this article is to measure the marital separation in Colombia in the period between 1951-2015, and to offer a corrected estimate of the presence of said phenomenon, at the municipal level, based on the 2005 Census. Direct and indirect techniques are applied to the calculation of the percentage of women aged 30 to 34 who were separated or divorced and also for those who had ever experienced such an event, regardless of their current marital status. The sources used were the Population Censuses from 1951 to 2005 and the National Demographic and Health Surveys for the period 1986-2015. The results indicate that, contrary to the under-registration of the Census, the separation has been increasing since 1986 to reach a level of 34\% in 2015. However, there are important territorial variations. Being the Caribbean, Pacific and Amazonia Orinoquia regions the places with the highest levels.

Keywords: Divorce; Marital Separation; Marital Status; Family Dissolution.

¿Cómo citar este artículo? / How to quote this article?

Ruiz-Vallejo, F. (2020). La separación conyugal en los Censos y en las Encuestas de Demografía y Salud en Colombia, 1951-2015. Sociedad y economía, (39), 155-182. https://doi.org/10.25100/sye.voi39.7913 


\section{Introducción}

A pesar de la relevancia de las separaciones conyugales en el análisis de los cambios demográficos de la región, existe un consenso sobre la escasez de trabajos en esta temática, especialmente si se compara con el volumen de investigaciones en otros campos de la nupcialidad (Cabella, 1998, 2008; Fussell y Palloni, 2004; García y Rojas, 2004; Rossetti, 1991). Ya desde los años ochenta, Goldman (1981) y Ojeda (1986) evidenciaban que tal vacío se debía principalmente a las limitaciones de las fuentes. En concreto, a la incapacidad de los censos y las estadísticas vitales para identificar uniones disueltas en aquellos individuos que, al momento del levantamiento de la información, se encontraban en segundas o posteriores uniones.

Ante dichas limitaciones la medición directa de la separación conyugal queda supeditada a la disponibilidad de encuestas poblacionales retrospectivas, que incluyan las historias de unión de la población. Sin embargo, este tipo de fuentes son escasas en la región (Goldman, 1981; Masciadri, 2002; Ojeda, 1986; Pérez y Ojeda, 2016; Zamudio y Rubiano, 1991), algo que obliga a los investigadores a recurrir a diversas estrategias y fuentes para aproximarse a su estudio, ya sea por medio de los censos de población (Masciadri, 2002; Sana, 2001) o de la combinación de tal fuente con encuestas transversales, entre las cuales se destaca la Encuesta de Demografía y Salud (DHS por sus siglas en inglés), disponibles en varios países de América Latina. Más allá de la fuente o el método utilizado, la mayoría de trabajos en la región coinciden en destacar el fuerte aumento de la separación conyugal (Binstock, 2004; Bucheli y Vigna, 2005; Cabella, 2010; Cabella, Peri, y Street, 2005; Flórez y Sánchez, 2013; Goldman, 1981; Ojeda, 1986; Ojeda y González, 2008; Pérez y Ojeda, 2016; Solís y Ferraris, 2014; Zamudio y Rubiano, 1991).

Teniendo en cuenta las potencialidades y limitaciones del Censo y las DHS, el artículo se plantea dos objetivos. El primero, estimar los niveles de separación conyugal en Colombia para el periodo 1951-2015; y el segundo, ofrecer una estimación municipal del fenómeno a través de un método de corrección del Censo de 2005 a partir de los datos de la DHS del mismo año. Siguiendo ejercicios similares (Esteve, García, y Mccaa, 2010), dicho método tiene en cuenta la participación de la unión consensual entre el total de uniones, y el porcentaje de separación conyugal de acuerdo al nivel educativo y el departamento de residencia. Para cumplir los dos objetivos se toman, por un lado, los datos de los Censos de población de 1951, 1964, 1973, 1985, 1993 y 2005; y, por otro, la versión colombiana de la DHS, denominada Encuesta Nacional de Demografía y Salud (ENDS), para los años 1986, 1990, 1995, 2000, 2005,2010 y $2015^{2}$. Adicionalmente, se incluye la Encuesta Nacional de Fecundidad (ENF) de 1976 para tener una estimación de mayor alcance.

Los cálculos se realizan para el grupo de mujeres entre 30 y 34 años con el fin de describir las variaciones temporales de la separación conyugal en el periodo de observación (19512015) y de comparar las estimaciones ofrecidas por cada fuente; así como las diferencias entre una medición centrada en el estado civil actual y otra basada en reportar la ruptura de una unión, experimentada alguna vez en la vida. El último tipo de indicador se vincula -regularmentecon encuestas retrospectivas, pero en este trabajo se ofrece una estimación a partir de un método indirecto basado en la información transversal de la ENDS. Tal como consta en los objetivos, el presente artículo se concibe como un aporte metodológico en términos de la medición de la separación conyugal. Por tanto, no plantea hipótesis explicativas sobre el fenómeno, y no explora la relación con otras variables sociodemográficas o territoriales en el mismo periodo. Un propósito así supera el alcance del presente estudio, y deberá abordarse en investigaciones futuras.

2 Las versiones de la encuesta de 1986 y 1990 se denominaron "Encuesta de Prevalencia, Demografía y Salud". En el presente artículo usaremos el acrónimo ENDS para referirnos a toda la serie colombiana de las DHS (19862015); y reservaremos el término "DHS" para indicar el proyecto internacional de este tipo de encuestas. Información disponible en: www.dhsprogram.com/ 
El presente trabajo usa el término "separación conyugal" para hacer referencia a las rupturas de las uniones estables, habiendo sido estas iniciadas mediante un matrimonio institucional (religioso o civil) o mediante una unión libre independientemente de si transitó o no, posteriormente, hacía un matrimonio. Tal consideración implica, a su vez, una mirada amplia del concepto de conyugalidad en los términos propuestos por Pedro Quintín (2008), quien entiende la relación conyugal como la cohabitación íntima continuada y socialmente reconocida, más allá de las expectativas de perdurabilidad de sus miembros.

El artículo se estructura en cinco secciones incluyendo la presente introducción. La segunda sección constituye una reflexión conceptual sobre la medición de la separación conyugal, a través del análisis de la pregunta del estado civil de los Censos de población a partir de 1951, cuando se incluyó por primera vez la categoría "separado", hasta el Censo de 2005. También se analizan las preguntas por los estados civiles y conyugales de la ENDS, desde la Encuesta Nacional de Fecundidad de 1976 hasta la última ENDS de 2015. La tercera sección describe la metodología, incluyendo las fuentes y las técnicas empleadas para obtener las estimaciones. La cuarta sección socializa los resultados obtenidos $y$, finalmente, el quinto apartado presenta las conclusiones del estudio destacando sus contribuciones y limitaciones, y las futuras líneas de investigación.

\section{La separación conyugal en los Censos de Población y en las encuestas de Fecundidad Demografía y Salud, 1951-2015}

A continuación, se hace una revisión detallada de las preguntas sobre el estado civil y la situación conyugal, disponibles en el Censo de población (1951-2005) y en las Encuestas de fecundidad, demografía y salud (1976-2015). Con ello, se ofrece una reconstrucción histórica de las categorías "divorcio" y/o "separación". Ambas disponibles en las dos fuentes de información y fundamentales para el conocimiento de las dinámicas de disolución de las uniones en el país.

\subsection{Cambios en las preguntas y definiciones de la separación conyugal en los Censos de Población entre 1951 y 2005}

La pregunta por el estado civil de la población se incluyó por primera vez en el Censo de 1870 (Estrada, 2017), aunque, un año antes, se había realizado un Censo en las Islas de San Andrés y San Luís de Providencia que permitió caracterizar a sus habitantes por sexo, grupo de edad, estado civil y profesión (Vidales, 1978). En los posteriores Censos de 1905, 1912, 1918, 1928 y 1938, los informes censales reportaban únicamente el nivel de soltería, matrimonio y viudez; y solo fue hasta el Censo de 1951 cuando se agregaron las categorías "separado" y "en unión libre" (Estrada, 2015)3.

Desde la inclusión de la categoría "separado" en la pregunta del estado civil, la definición de dicho estado ha venido cambiando a lo largo del tiempo en respuesta a dos procesos sociales relacionados entre sí. Por un lado, a los cambios jurídicos en la regulación de la disolución legal de los matrimonios $\mathrm{y}$, por otro, al progresivo reconocimiento de la unión libre como forma de conyugalidad $\mathrm{d}^{4} \mathrm{Al}$ analizar la relación entre la separación conyugal y la progresiva aceptación de la unión libre como forma alterna o paralela al matrimonio, llama la atención la historia común de las dos categorías a lo largo de los censos. Una de tales particularidades es que ambos estados conyugales se incluyeron por primera vez en el Censo de 1951. Sin embargo, si una unión libre se disolvía y la persona estaba "separada" en el

3 En el anexo 7 del trabajo referenciado se incluye una recopilación sistemática de la variable estado civil y otras variables de caracterización de la población de los censos de la primera mitad del siglo XX (Estrada, 2015). Agradecemos a la autora haber compartido su experticia histórica en este punto, y por el material compartido.

4 Los cambios en la pregunta del estado civil, así como las definiciones operativas incluidas en los manuales de los Censos, se recopilan en un cuadro comparativo del que dispone el autor, previa solicitud por correo electrónico. 
momento del Censo, no podía declararse como tal porque dicha categoría estaba reservada -únicamente- a "los casados legalmente que no hacían vida marital" (DANE, 1954, p. 9). En el Censo de 1964, la definición fue ampliada para especificar que la separación de facto no fuera por "causas distintas de la ausencia temporal por trabajo, vacaciones, licencia, negocio, etc." (DANE, 1964, p. 17).

El tratamiento diferenciado de la unión libre respecto al matrimonio se observa en la definición operativa de la categoría en el Censo de 1964. El Manual de instrucciones para los empadronadores indicaba que la casilla "unión libre" se seleccionaba, únicamente, "si la persona vive como casada sin serlo o sea que vive como marido o esposa sin haber legalizado la unión" (DANE, 1964, p. 17). Detrás de dicha definición se entrevé la ambigüedad con la que era tratado aquel estado civil, pues a pesar de reconocer que sus miembros se podían comportar "como marido o esposa", no era una unión homologable al matrimonio dada la ausencia de un vínculo legal. En el Censo de 1964, la definición del estado "soltero" amplió su definición para que, además de incluir a la persona "que nunca se ha casado", se considerase como tal a quien a la fecha censal "no vive en unión libre, o sea como casada si serlo" (DANE, 1964, p. 17). En el Censo anterior (1951), los solteros eran aquellos "que nunca se habían casado" (DANE, 1954, p. 9).

A partir del Censo de 1973, la categoría "separado" se convierte en "separado o divorciado". Algo que, como se mencionó anteriormente, da cuenta de los cambios jurídicos que experimentaba el país, pero también de la progresiva aceptación de la unión libre como forma de conyugalidad que, una vez disuelta, transita al estado civil "separado" y no al "soltero", como ocurría anteriormente. El manual del Censo de 1973, consideraba a una persona como separada o divorciada si se encontraba en tres condiciones, siempre y cuando el motivo no fuera por razones de trabajo, vacaciones, enfermedad, entre otros. Dichas circunstancias eran:

- "Aquellas personas que, habiendo vivido en unión libre, en el momento del Censo no viven con su compañera(o).
- Aquellas personas casadas civil y/o religiosamente, pero que en el momento del Censo no viven con su compañero(a).

- Aquellas personas cuyo matrimonio fue disuelto por medios legales y que no se han vuelto a casar ni viven en unión libre" (DANE, 1973, p. 42).

En el Censo de 1985 la definición se conserva en los mismos términos al censo anterior, pero se suprime el adjetivo "religioso" para eliminar la distinción entre este tipo de matrimonio y el de tipo civil. En los siguientes dos Censos (1993 y 2005) la definición adquiere un tinte "homologador" de la unión libre y el matrimonio como forma permanente de conyugalidad, pues conceptualizan que un "separado(a) o divorciado(a)" es la "persona cuya unión (casado o en unión libre) ha sido disuelta por vía legal o de hecho y no se ha vuelto a casar, ni vive en unión libre" (DANE, 1993, p. 169; 2005, p. 438)5.

Por su parte, los ajustes en la definición de la "unión libre" como estado civil se aprecian en los cambios en la delimitación de sus fronteras. Si bien, tanto en el Censo de 1993 como en el de 2005, las personas en unión libre son aquellas que viven en unión marital sin que exista vínculo matrimonial civil o religioso y cuya unión es de carácter estable; el primero de ellos agrega la condición de haber "constituido una familia", la cual se suprime en el Censo de 2005 (DANE, 2005). Aunque no se incluye en la definición operativa, en las categorías del cuestionario del Censo de 2005 se establece una duración de dos años como criterio taxativo de las uniones libres, mediante la formulación de dos opciones de respuesta en la pregunta del estado civil (DANE, 2005, p. 362):

- No está casado y lleva dos años o más viviendo con su pareja ${ }^{6}$.

5 El resaltado en negrilla es propio.

6 De acuerdo con el artículo 2do de la Ley 979 de 2005 (que modifica la Ley 54 de 1990) la unión libre sostenida por un término igual o posterior a dos años crea una sociedad patrimonial entre los compañeros permanentes (República de Colombia, 2005). 
- No está casado y lleva menos de dos años viviendo con su pareja.

La revisión de los cuestionarios y manuales operativos de los Censos posteriores a la segunda mitad del siglo XX (DANE, 1954; 1964; 1973; 1985; 1993; 2005), sugieren la existencia de una historia paralela entre los cambios en la forma de concebir la separación conyugal, con la emergencia y el desarrollo de la unión libre como estado civil en los censos de población. Esta mutua relación se expresa en la progresiva inclusión de las uniones libres que se disuelven en la categoría "separado o divorciado" y no como "soltero", tal como ocurría antes de 1973. Así las cosas, la evidencia sugiere que la historia de la separación conyugal en los censos es la lucha misma de las uniones libres por dejar su huella en las radiografías de la población.

El uso de fuentes censales para la estimación de las separaciones conyugales tiene varios inconvenientes. En primer lugar, no considera el orden de la unión, pudiendo tal estar afectado por las uniones (o separaciones conyugales) sucesivas (Flórez y Sánchez, 2013). En segundo lugar, existe un problema de registro dada la heterogeneidad de los censos de la región para diferenciar el estado civil "separado/a" (no legal) y/o "divorciado/a" (usualmente reservado a la disolución legal del vínculo conyugal), y su correspondiente limitación para captar los cambios entre estados conyugales. Por ejemplo, cuando en México se incluyó, a partir de 1921, la pregunta por el estado civil en los censos de población los dos estados civiles eran parte de una misma categoría. Entre 1930 y 1960 solo se captaron los divorcios y a partir de 1970 se agregó la opción "separado" como categoría propia (Ojeda, 1986).

Los problemas del censo para registrar el nivel de separación conyugal obedecen principalmente a la combinación que algunos países hacen de los estados civiles legales y los estados conyugales de facto, lo cual se expresa en la falta de categorías excluyentes en la pregunta del estado civil (Masciadri, 2017). Al analizar el censo argentino de 1991, Masciadri (2002) señala que la subestimación del porcentaje de personas separadas y divorciadas se genera por dos situaciones:

- Cuando las personas con alguna separación o divorcio se declaran en unión libre por tener una pareja corresidente en la fecha censal.

- Cuando las personas casadas experimentan una separación de hecho al no haber disuelto el vínculo legal en el momento del censo, y se declaran como "casadas". Esto podría ser incluso más agudo en contextos más tradicionales donde el divorcio puede estar altamente estigmatizado.

Sin embargo, y pese a todas las limitaciones, algunos investigadores reivindican la utilidad de la información censal para contar con estimaciones aproximadas del nivel de separación conyugal actual (Masciadri, 2002), especialmente en escalas territoriales pequeñas como municipios o localidades, para las cuales las encuestas probabilísticas no son representativas ${ }^{7}$.

\subsection{La separación conyugal en las encuestas de fecundidad, demografía y salud, 1976-2015}

Las Encuestas de Demografía y Salud también han documentado el estado civil y las experiencias de conyugalidad de la población en edad reproductiva. Desde la Encuesta Nacional de Fecundidad (ENF) de 1976 (correspondiente a la versión colombiana de la Encuesta Mundial de Fecundidad), se han incluido preguntas de control para identificar tanto a las mujeres "nunca unidas" -entre quienes reportaban estar "solteras"- como a las que habían tenido una única unión entre todas las mujeres alguna vez unidas. De tal manera, tanto la ENF de 1976 como

7 El 4 de julio de 2019, el DANE presentó los resultados definitivos del Censo de población de 2018. Dicho Censo no fue incluido en el presente estudio dado que su realización fue posterior a la formulación y desarrollo de la investigación. Una vez se publiquen los microdatos de la muestra censal, valdría la pena incluirlos en posteriores análisis demográficos sobre la separación conyugal. 
las ENDS de 1986, 1990, 1995, 2000, 2005, 2010, y 2015 constituyen instrumentos relevantes para la estimación de la separación conyugal, y para el estudio de sus dinámicas temporales desde la segunda mitad del siglo XX hasta nuestros días.

A diferencia de otras encuestas probabilísticas de carácter nacional con representatividad regional y/o departamental, las ENDS incluyen preguntas adicionales que permiten estimaciones más confiables sobre el estado civil de la población. En este sentido, desde la ENF de 1976, considerada como el antecedente de las ENDS, junto con la pregunta por el estado civil se cuenta con variables que identifican a las mujeres "nunca unidas" entre quienes se declaran "solteras" y también el número de uniones de aquellas que alguna vez se habían unido. Su consistencia en el tiempo permite reconstruir las tendencias de la separación conyugal a lo largo de 39 años (desde 1976 hasta la última ENDS de 2015).

Para determinar el estado civil, la ENDS combina preguntas de corte retrospectivo, que indagan sobre experiencias conyugales pasadas, con interrogantes de tipo transversal sobre un estado particular al momento de la encuesta. En el caso de las ENDS de 1986 y 1990, primero se identificaba si la mujer había estado en unión (incluyendo matrimonio y unión libre), mediante la pregunta "¿Alguna vez ha estado casada o viviendo con un hombre?" $\mathrm{y}$, posteriormente, entre quienes respondían afirmativamente, se establecía si actualmente la entrevistada estaba casada, en unión libre, viuda, separada o divorciada. Entre quienes respondían negativamente a la pregunta, se clasificaba como "nunca unida". Contrario al Censo, todas las ENDS diferencian el estado civil "separada" de "divorciada", y también se destaca que sólo la ENDS de 1990 incluyó tres

8 Las dos preguntas de la ENDS son: 1) ¿Ha estado usted Casada o unida alguna vez? Para quienes respondían "sí", se pregunta, 2) ¿Cuál es su estado civil actual? La respuesta incluye cinco opciones: casada, unión libre, viuda, divorciada, y separada. El cuadro comparativo de las preguntas y opciones de respuesta de las ocho encuestas analizadas, puede ser solicitado al autor por correo electrónico. categorías de matrimonio: el religioso, el civil; y el civil y religioso. Tal forma de indagar por el estado civil revierte el orden de las preguntas de la ENF de 1976 en la que, luego de establecer el estado actual, confirmaba que quienes se declaraban como "solteras" no hubieran estado unidas anteriormente.

El cuestionario de 1995 modificó nuevamente la forma de indagar por el estado civil. A partir de entonces, y hasta la última versión de 2015 , se pregunta primero si la mujer al momento de la entrevista se encuentra casada, en unión libre, o si no vive con alguna pareja. Para quienes marcan la última opción, se indaga por experiencias previas de matrimonio o de unión libre o si, por el contrario, confirman que nunca se han unido. Entre quienes sí reportan haberlo hecho, se pregunta por el estado actual de esa unión disuelta, con la posibilidad de elegir una de las siguientes opciones: viuda, separada o divorciada.

Por otro lado, todas las encuestas analizadas permiten identificar el porcentaje de mujeres alguna vez unidas que declaraban uniones de segundo o ulterior orden. Sin embargo, entre 1986 y 2010 dicha pregunta solo tenía dos opciones de respuesta: haber tenido una unión o haber tenido más de una. Y, aunque se cuenta con la fecha de inicio de la primera unión, no se registra la fecha de su disolución, ni se establece si fue por motivos de separación conyugal, por viudez o por abandono/migración.

Así, mediante esta serie de encuestas, es posible medir tanto la "separación conyugal" como un estado declarado en un momento particular, o como un evento experimentado alguna vez en la vida. En el último caso, la estimación se puede hacer de forma directa por medio de las historias de unión de la ENF de 1976 y la ENDS de 2015, o mediante una aproximación indirecta a través de la información sobre experiencias pasadas de conyugalidad (del tipo "ha estado usted unida alguna vez"), disponibles en todas las ocho encuestas; tal como se ha realizado para otras regiones del mundo con DHS (Clark y BraunerOtto, 2015). 
Como se mencionó en la introducción, la forma adecuada de medir la separación conyugal de la primera unión es mediante el uso de encuestas longitudinales, especialmente en países como Colombia en donde la no institucionalidad de las uniones ha estado presente desde hace muchos años (Saavedra, Esteve y López-Gay, 2013). En este sentido, la DHS constituye un recurso importante para el estudio de las dinámicas conyugales y familiares que, en parte, subsanan las restricciones de los datos transversales como el censo u otras encuestas. Si bien la DHS incluye las historias reproductivas de las mujeres, no indagan por la historia de unión, así como tampoco por la fecha y el motivo de la primera disolución, sobre la cual sí recoge la fecha de inicio de la primera unión. Por lo tanto tal fuente tampoco permite la estimación directa de la separación conyugal (Abalos, 2017; Clark y Brauner-Otto, 2015; Flórez y Sánchez, 2013), aunque incluye preguntas que permiten calcular medidas aproximadas a partir de la indagación sobre las experiencias de conyugalidad pasadas, si estas han sido solo una o más de una, y el estado conyugal actual.

En las dos secciones precedentes, se ha demostrado que la ENF y las ENDS constituyen fuentes de información privilegiadas para el estudio de la separación conyugal, determinando no solo sus niveles a escala nacional y regional, sino también sus variaciones temporales. Una de sus principales ventajas, frente al Censo, es la identificación de las mujeres nunca unidas como una mejor medición de la soltería; entendiendo esta como la no transición hacía cualquier forma de conyugalidad corresidente. La prerrogativa de la ENDS respecto al Censo es la base del método propuesto por Esteve et al. (2010), con el fin de corregir la sobrestimación de la soltería hecha por los Censos en América Latina.

Dicha solución emerge al constatarse empíricamente la presunta experiencia de cohabitación de las mujeres solteras con hijos, aunque, tal como afirman los autores, estas diferencias entre los datos del Censo y de las DHS aumentan con la edad y disminuyen con los años de escolaridad (Esteve et al., 2010). Sin embargo, es probable que una parte importante del grupo sean mujeres con uniones libres disueltas, que se declaran como solteras en el censo, pero que en las $D H S$, gracias a las preguntas por experiencias pasadas de unión, no entrarían en el grupo de mujeres nunca unidas. De allí la importancia de considerar la declaración de otros estados civiles en el estudio de la separación conyugal.

A pesar de las ventajas de las ENDS para el estudio de la separación conyugal, estas tienen las limitaciones propias de sus diseños muestrales e impiden la estimación de unidades territoriales menores como los municipios. El nivel más bajo al que desagrega la información es el departamento", aunque solo a partir de 2005. Antes de tal año, la subregión era la escala más baja de desagregación, y desde la ENF de 1976 se ofrecen estimaciones para cinco regiones del país. En este punto, el censo constituye una fuente privilegiada para la estimación municipal de la separación conyugal, imposible de estimar con las encuestas actuales.

Tan solo una ENDS de 2005 coincide con el Censo del mismo año. Tal particularidad de las fuentes nos permite usarlas de forma complementaria para ajustar las estimaciones municipales de la separación conyugal actual. Esto a partir de un método de corrección que tiene en cuenta el subregistro de tal categoría en el Censo que, como veremos a continuación, varía en función del nivel de cohabitación, el nivel educativo y el departamento de residencia. En el siguiente apartado se detallan los procedimientos metodológicos adoptados para el cumplimiento de los objetivos propuestos y se presenta las estimaciones respectivas.

\section{Metodología}

Para el cumplimiento de los objetivos se emplearon varios procedimientos estadísticos en la estimación de la separación conyugal. Todos los cálculos se realizaron para el grupo de mujeres de 30 a 34 años por ser un segmento de la población

9 De acuerdo a la Constitución Política de 1991, los departamentos son las unidades territoriales de primer nivel en Colombia. La división política y administrativa del país incluye 32 departamentos y un distrito capital (DANE, 2005). 
alguna vez unida, expuesta lo suficiente al riesgo de haber disuelto su primera unión de forma voluntaria y no por viudez. Adicionalmente, es un grupo intermedio entre un nivel bajo de soltería y uno también bajo segundas o posteriores uniones, lo cual reduce el riesgo de subregistro de la disolución de quienes al momento de la encuesta se encontraban en una segunda unión. Finalmente, considerando que el principal aporte del estudio es la identificación de tendencias territoriales y temporales, tomar tal grupo de edad es un recurso analítico para observar los cambios en los niveles de la separación conyugal en un mismo grupo de edad en el tiempo.

La metodología del estudio se estructura en dos componentes. El primero se plantea con el fin de generar estimaciones para todo el periodo de observación (1951-2015), de acuerdo a dos tipos de mediciones de la separación conyugal: a) el porcentaje de mujeres del grupo de edad 30-34 años que, en la fecha censal o de la encuesta, manifiestan dicho estado; y b) el porcentaje de mujeres alguna vez unidas (manteniendo el mismo grupo de edad) que habían experimentado la disolución de al menos una unión, sin importar el estado conyugal actual. Por su parte, el segundo componente de la metodología propone un método de ajuste para corregir la subestimación censal de la separación conyugal actual a nivel municipal. Dado que el Censo y la ENDS coinciden por única vez en $\mathbf{2 0 0 5}$, se hace un uso combinado de ambas fuentes para tener una estimación más precisa de la separación en este nivel territorial. En aras de tener mayor claridad metodológica, la Tabla 1 relaciona los objetivos de la investigación con los componentes, los indicadores, las fuentes, los periodos y las unidades territoriales de las estimaciones.

\subsection{Primer componente: la medición de la separación conyugal entre 1951 y 2015}

Tabla 1. Relación de los componentes de la metodología de acuerdo a los objetivos

\begin{tabular}{|c|c|c|c|c|}
\hline $\begin{array}{c}\text { Objetivo y } \\
\text { Componente }\end{array}$ & Indicadores & Fuente(s) & Periodo & $\begin{array}{c}\text { Unidad } \\
\text { territorial }\end{array}$ \\
\hline \multirow{2}{*}{$\begin{array}{l}\text { 1. Estimar los } \\
\text { niveles de } \\
\text { separación } \\
\text { conyugal, 1951-2015. }\end{array}$} & $\begin{array}{l}\text { a) Porcentaje de } \\
\text { mujeres ( } 30-34 \text { años) } \\
\text { actualmente separadas/ } \\
\text { divorciadas. }\end{array}$ & $\begin{array}{l}\text { - Censos de población } \\
\text { de } 1951,1964,1973,1985, \\
1993 \text { y } 2005 . \\
\text { - ENF de } 1976 . \\
\text { - ENDS de 1986, 1990, } \\
\text { 1995, } 2000,2005,2010 \\
\text { y } 2015 .\end{array}$ & $1951-2015$ & $\begin{array}{l}\text { - Nacional. } \\
\text { - } 6 \text { regiones. }\end{array}$ \\
\hline & $\begin{array}{l}\text { b) Porcentaje de } \\
\text { mujeres alguna vez } \\
\text { unidas con al menos } \\
\text { una experiencia de } \\
\text { separación conyugal. }\end{array}$ & $\begin{array}{l}\text { - } \quad \text { ENF de } 1976 . \\
\text { - ENDS de 1986, 1990, } \\
\text { 1995, 2000, 2005, } 2010 \\
\text { y } 2015 .\end{array}$ & $1976-2015$ & - Nacional. \\
\hline $\begin{array}{l}\text { 2. Estimar el } \\
\text { nivel ajustado } \\
\text { de separación } \\
\text { conyugal actual, a } \\
\text { nivel municipal. }\end{array}$ & $\begin{array}{l}\text { Porcentaje de } \\
\text { mujeres (30-34 años) } \\
\text { actualmente separadas/ } \\
\text { divorciadas. }\end{array}$ & $\begin{array}{l}\text { - Censo de } 2005 . \\
\text { - ENDS de } 2005 .\end{array}$ & 2005 & $\begin{array}{l}\text { - Municipal (430 } \\
\text { municipios). }\end{array}$ \\
\hline
\end{tabular}

Fuente: elaboración propia 
Tal como consta en la Tabla 1, las estimaciones de este componente incluyen indicadores de dos tipos. Uno de corte transversal, correspondiente al porcentaje de mujeres de 30 a 34 años de edad que, en el momento del Censo o de la ENDS, declara estar separada o divorciada; y una segunda estimación de tipo longitudinal, que, a través de un método indirecto, mide el porcentaje de mujeres con al menos una disolución entre las mujeres alguna vez unidas.

Las variables dependientes son los estados civiles/conyugales tanto del Censo como de la ENDS. De acuerdo a la fuente y el tipo de medida, las equivalencias de los estados civiles/ conyugales (transversal y longitudinal) es la siguiente:

- Solteras o nunca unidas: se compara la proporción de solteras del Censo y la de las mujeres "nunca unidas" de la ENDS, de acuerdo a la evolución de las preguntas relacionadas con el estado civil/conyugal.

- Unidas: corresponde a las mujeres que al momento de la entrevista se declaran casadas o en unión libre según los términos en que cada fuente lo define en sus distintas versiones. En el caso de las que nunca disolvieron su primera unión, se denomina "en unión sin experiencia de separación conyugal".

- Separadas/divorciadas: mujeres que han disuelto su matrimonio o su unión libre y que al momento de la entrevista se consideran como tal. En términos retrospectivos, pertenecen a este grupo quienes han experimentado la separación conyugal de su primera unión, sin importar el estado civil actual. En nuestros resultados esta categoría figura como "alguna vez separada/ divorciada".

- Viudas: similar a la definición del grupo anterior, corresponde a las mujeres que no continúan en unión por la muerte de su pareja y que se encuentran como tal al momento del censo/encuesta. Como dato retrospectivo, concierne a quienes experimentaron tal evento en su primera unión, más allá del estado civil actual. Este grupo lo denominamos "alguna vez viudas".

Las variables independientes son: el nivel educativo, la región y el departamento de residencia. Adicionalmente, se incluyó información sobre los hijos para las mujeres solteras. Los cálculos no se hicieron para los hombres porque la ENDS de 2005 no los incluye en su muestra individual. En la Tabla 2 se describen las variables del análisis.

\subsubsection{La medición trasversal}

Para la estimación de la separación conyugal como un estado, reportado por las mujeres al momento de la entrevista, se calculó la distribución del estado civil de los Censos del periodo 1951-2005 y de la serie de ENDS 19862015, además de la ENF de 1976. En el caso de las solteras o nunca unidas, se distinguió entre mujeres con o sin hijos. De tal manera se describe la evolución histórica de los estados civiles y se resalta la discrepancia en la proporción de separación conyugal entre ambas fuentes. Posteriormente, se presentan tablas cruzadas con las variables nivel educativo y región, a fin de identificar las diferencias en los valores reportados. Es importante advertir que en todos los casos las estimaciones se hicieron aplicando los ponderadores tanto de las muestras censales como de las encuestas.

\subsubsection{La medición longitudinal indirecta}

La estimación de la separación conyugal desde un enfoque longitudinal se hace a través del método indirecto propuesto por Clark y Brauner-Otto (2015). Los autores, a partir de las preguntas de nupcialidad de la DHS, estimaron, para 33 países de África Subsahariana, la proporción de mujeres alguna vez separadas o divorciadas, de acuerdo al tiempo transcurrido desde la primera unión. Dicho método estima el nivel de separación conyugal a partir de dos grupos de mujeres identificadas en la DHS. Por un lado, aquellas que declaran una única unión y que en la pregunta del estado civil indican estar separadas o divorciadas; $y$, por otro, a las 


\begin{tabular}{|c|c|c|c|}
\hline Variable & Categoría & Censo $2005^{*}$ & ENDS 2005 \\
\hline \multirow{6}{*}{$\begin{array}{l}\text { Nivel } \\
\text { educativo }\end{array}$} & $\begin{array}{l}\text { Sin educación } \\
\text { o con primaria } \\
\text { incompleta }\end{array}$ & $\begin{array}{l}\text { - } 0-4 \text { años de escolaridad. } \\
\text { - Personas con algún grado de } \\
\text { escolaridad primaria. }\end{array}$ & $\begin{array}{l}\text { - 0-4 años de } \\
\text { escolaridad. }\end{array}$ \\
\hline & $\begin{array}{l}\text { Primaria completa } \\
\text { o secundaria } \\
\text { incompleta }\end{array}$ & $\begin{array}{l}\text { - } \text {-10 años de escolaridad. } \\
\text { después de la primaria, o con grado de } \\
\text { escolaridad secundaria. }\end{array}$ & $\begin{array}{l}\text { - 5-10 años de } \\
\text { escolaridad. }\end{array}$ \\
\hline & $\begin{array}{l}\text { Secundaria } \\
\text { completa }\end{array}$ & - 11 años de escolaridad. & - 11 años de escolaridad. \\
\hline & $\begin{array}{l}\text { Superior a } \\
\text { secundaria } \\
\text { completa }\end{array}$ & $\begin{array}{l}\text { - 12-18 años de escolaridad o más. } \\
\text { - Personas con algún grado de } \\
\text { escolaridad terciaria. }\end{array}$ & $\begin{array}{l}\text { - 12-18 años de } \\
\text { escolaridad o más. }\end{array}$ \\
\hline & Desconocido & NA & NA \\
\hline & $\begin{array}{l}\text { Nota: por el reduci } \\
\text { la estimación muni } \\
\text { educativos: primari }\end{array}$ & $\begin{array}{l}\text { o tamaño de la muestra de la ENDS, en el mé } \\
\text { ipal de la separación conyugal se usaron, ún } \\
\text { (o a } 5 \text { años de escolaridad), secundaria (6-11) }\end{array}$ & $\begin{array}{l}\text { todo de ajuste de } \\
\text { camente, } 3 \text { niveles } \\
\text { superior }(12+) \text {. }\end{array}$ \\
\hline \multirow{7}{*}{$\begin{array}{l}\text { Región y } \\
\text { departamento }\end{array}$} & Atlántica & $\begin{array}{l}\text { Conformada por } 8 \text { departamentos: } \\
\text { Atlántico, Bolívar, Guajira, Cesar, Córdoba, } \\
\text { Magdalena, San Andrés y Sucre. }\end{array}$ & Ídem. \\
\hline & Oriental & $\begin{array}{l}\text { Conformada por } 5 \text { departamentos: Boyacá, } \\
\text { Cundinamarca, Meta, Norte de Santander } \\
\text { y Santander. }\end{array}$ & Ídem. \\
\hline & Central & $\begin{array}{l}\text { Conformada por } 7 \text { departamentos: } \\
\text { Antioquia, Caldas, Caquetá, Huila, } \\
\text { Quindío, Risaralda y Tolima. }\end{array}$ & Ídem. \\
\hline & Pacífica & $\begin{array}{l}\text { Conformada por } 4 \text { departamentos: Cauca, } \\
\text { Chocó, Nariño y Valle del Cauca. }\end{array}$ & Ídem. \\
\hline & Bogotá & Bogotá. & Ídem. \\
\hline & $\begin{array}{l}\text { Orinoquía y } \\
\text { Amazonía }\end{array}$ & $\begin{array}{l}\text { Conformada por } 8 \text { departamentos: } \\
\text { Amazonas, Arauca, Casanare, Guainía, } \\
\text { Guaviare, Putumayo, Vaupés y Vichada. }\end{array}$ & Ídem. \\
\hline & Desconocido & NA. & NA. \\
\hline Municipio & $\begin{array}{l}\text { Lista de } \\
\text { municipios }\end{array}$ & $\begin{array}{l}\text { Clasificación de los municipios disponible } \\
\text { en la muestra del Censo de IPUMS-I. }\end{array}$ & NA. \\
\hline \multirow{3}{*}{ Hijos } & Sin hijos & $\begin{array}{l}\text { Solteras que reportan no haber tenido } \\
\text { algún hijo o hija. }\end{array}$ & $\begin{array}{l}\text { Mujeres nunca unidas } \\
\text { que reportan no haber } \\
\text { tenido algún hijo o hija. }\end{array}$ \\
\hline & Con hijos & $\begin{array}{l}\text { Solteras que reportan haber tenido algún } \\
\text { hijo o hija. }\end{array}$ & $\begin{array}{l}\text { Mujeres nunca unidas } \\
\text { que reportan haber } \\
\text { tenido algún hijo o hija. }\end{array}$ \\
\hline & Desconocido & No disponible. & No disponible. \\
\hline
\end{tabular}

Nota: *de acuerdo a la armonización de las variables realizada por IPUMS-i.

Fuente: elaboración propia partir de la documentación de IPUMS-i (Minnesota Population Center, 2018). 
mujeres con dos o más uniones que habrían terminado su unión de forma voluntaria y no por viudez. Sin embargo, dado que la DHS no indaga por el motivo de la disolución, el método debe distinguir estos dos subgrupos calculando la proporción de separación conyugal y de viudez entre las mujeres que conformaron segundas o posteriores uniones, las cuales por un efecto de la edad van cambiando con el tiempo.

Por otra parte, en el caso de Colombia, hay una ventaja que no tienen otros países con $D H S$ que consiste en la disponibilidad de módulos de historias de unión en la ENF de 1976 y en la ENDS de 2015. De tal manera, es posible calcular la separación conyugal de forma directa y comparar sus resultados con los obtenidos por el método antes descrito. Así, en la presente investigación, las dos encuestas se usan como instrumentos de "calibración" de la aproximación indirecta, permitiendo con ello la cuantificación de su eficacia para posteriormente poder replicarlo en las ENDS del periodo 1986-2010 que, como ya se mencionó, no incluyeron datos sobre la historia de unión.

Siguiendo el método propuesto por Clark y Brauner-Otto (2015), se presenta una adaptación sencilla para la inclusión de todos los estados conyugales, desde una perspectiva biográfica, en los términos concebidos en el presente trabajo.

$$
S C \_p r i U_{34}=S C \_a c t u a l_{34}^{\text {priU }}+\sum_{19}^{34}\left(\frac{S C_{\text {actual } x}^{\text {priU }}}{S C_{\text {actual } x}^{\text {priU }}+V_{\text {actual } x}^{\text {pri }}} \cdot \Delta U^{2+U}\right)
$$

Donde:

- $\quad S C \_p r i U_{34}=$ Proporción de mujeres del grupo de edad 30-34 alguna vez separadas o divorciadas.

- $\quad S C \_a c t u a l_{34}^{p r i U}=$ Proporción de mujeres del grupo de edad 30-34 que reportan una única unión, y que se encuentran actualmente separadas o divorciadas.

- $\quad S C \_a c t u a p_{\mathrm{x}}^{p r i U}=$ Proporción de mujeres del intervalo de edad quinquenal $x$, que reportan una única unión, y que al momento de la encuesta declaran estar separadas o divorciadas.

- $\quad V_{-}$actualpriu $=$Proporción de mujeres del intervalo de edad quinquenal $x$, que reportan una única unión, y que al momento de la encuesta declaran estar viudas.

- $\Delta U^{2+U}=$ Diferencia entre la proporción de mujeres alguna vez unidas que reportan 2 o más uniones, del intervalo $x+n$ con respecto al intervalo $x$.

A partir de 1 se obtienen, también, otras dos proporciones: la de mujeres en unión sin experiencia de separación conyugal y la de mujeres alguna vez viudas, así:

$$
\begin{gathered}
U_{-} p_{\text {ri }} U_{34}=U_{-} \text {actual }_{34}^{\text {priU }} \\
V_{-} \text {priU }_{34}=1-U \_p r i U_{34}-S C \_p r i U_{34}(3)
\end{gathered}
$$

Donde:

- $\quad U_{-} p r i U_{34}$ y $V_{-} p r i U_{34}$ : Proporción de mujeres del grupo $30-34$ años actualmente unidas sin experiencia de separación conyugal y de mujeres alguna vez viudas.

- $\quad$ U_actual priv= Proporción de mujeres del grupo 30-34 años actualmente unidas que reportan una única unión.

- $\quad S C \_p r i U_{34}=$ Proporción de mujeres del grupo de edad 30-34 años alguna vez separadas o divorciadas. 
Para obtener la distribución de los estados conyugales de acuerdo al desenlace de la primera unión, es decir, el haber experimentado la separación conyugal o la viudez, se multiplican las proporciones obtenidas en las fórmulas 1 , 2 y 3 entre las mujeres alguna vez unidas del grupo de edad 30-34. De tal manera, se estiman las proporciones de cuatro estados conyugales desde un enfoque biográfico: a) nunca unidas, b) actualmente unidas sin experiencia de separación conyugal, c) alguna vez separadas o divorciadas, y d) alguna vez viudas.

Cuando se comparan los resultados obtenidos de forma directa con los resultados del método indirecto, se observan valores muy cercanos de la separación conyugal, especialmente para la ENDS de 2015 en la que el método estima en 0,10 puntos porcentuales adicionales dicho estado (ver Tabla 3). Usando la ENF de 1976 la sobrestimación es levemente mayor $(1,03)$, pero en ambos casos la aproximación es altamente confiable, pues los resultados del método indirecto eran un $6 \%$ más altos en la encuesta de 1976 y un 0,3\% en la de 2015. Si comparamos la exactitud de los otros estados conyugales, se confirma que esta aproximación es eficiente para la separación, pero no para la viudez. El método tan solo capta el $63 \%$ de la viudez reportada de forma directa por la ENF de 1976 y el $66 \%$ por la ENDS 2015, posiblemente por la no operación adecuada del método en porcentajes en fenómenos de baja presencia poblacional como la viudez. En el caso de las mujeres que se han unido una única vez y continúan en dicho estado, el método calcula el $99 \%$ del valor "real" para 1976 y sobrestima en 0,6 puntos porcentuales el valor encontrado en 2015; aunque sigue siendo altamente eficiente.

\subsection{Segundo componente: la estimación municipal de la separación conyugal actual}

Tal como fue mencionado en los apartados 2.1 y 2.2, el Censo es la única fuente válida para estimar la separación conyugal actual en los municipios. Sin embargo, este ofrece valores que subestiman los niveles de dicho estado civil, pero que pueden ser ajustados tomando la ENDS de 2005 como instrumento de corrección, a partir de sus estimaciones departamentales.

El método se basa en la modelación lineal de la diferencia, entre el nivel de separación/ divorcio del Censo y de la ENDS de 2005, de tres niveles educativos en cada una de las 33 unidades territoriales analizadas (32 departamentos y Bogotá en calidad de Distrito Capital) para las cuales la última fuente desagrega la información. Una vez obtenida la predicción de la diferencia

Tabla 3. Estimación indirecta y directa de la distribución porcentual de los estados conyugales experimentados alguna vez en la vida. Mujeres 30-34 años. Colombia, 1976 y 2015

\begin{tabular}{lrrrrrrr}
\hline \multirow{2}{*}{ Estado conyugal } & \multicolumn{3}{c}{ ENF 1976 } & \multicolumn{3}{c}{ ENDS 2015 } \\
\cline { 2 - 8 } & Indirecto & Directo & Diferencia & Indirecto & Directo & Diferencia \\
\hline Nunca unida & 11,4 & 11,4 & 0,0 & 16,1 & 16,1 & 0,0 \\
En única unión & 69,6 & 69,8 & 0,2 & 48,2 & 47,6 & $-0,6$ \\
$\begin{array}{l}\text { Alguna vez en separación } \\
\text { conyugal }\end{array}$ & 17,6 & 16,5 & $-1,0$ & 34,3 & 34,2 & $-0,1$ \\
Alguna vez en viudez & 1,5 & 2,3 & 0,9 & 1,4 & 2,2 & 0,7 \\
Total & 100,0 & 100,0 & 0,0 & 100,0 & 100,0 & 0,0 \\
\hline
\end{tabular}

Fuente: elaboración propia a partir de la ENF de 1976 (OPR, 2017) y la ENDS 2015 (Profamilia, Ministerio de Salud y Protección Social, e ICF, 2017a). 
según el nivel educativo y el departamento, dicho factor se suma al valor observado de separación conyugal en el municipio. La formulación es la siguiente:

$$
\text { Diferencia_SC_34 } \text { depto }_{\text {esc }}=K+\beta_{\text {depto }}+\beta_{\text {esc }}+U m u n_{\text {censo }}+U L m u n_{\text {censo }}
$$

Donde:

- Diferencia_SC_34 $\underset{\text { depto }}{\text { esc }}=$ Diferencia entre la ENDS y el Censo, de la proporción de separación conyugal actual de las mujeres del grupo 30-34 años, del nivel educativo esc, en el departamento depto.

- $\quad K=$ es la constante del modelo de regresión lineal.

- $\quad \beta_{\text {depto }}=$ Coeficiente de cada departamento (33 en total)

- $\quad \beta_{\text {esc }}=$ Coeficiente de cada nivel educativo (3 en total)

- Umun $_{\text {censo }}=$ Proporción de mujeres del grupo 25-29 que reportan estar unidas al momento del Censo.

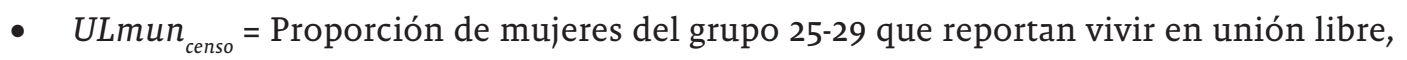
sobre el total de uniones.

A partir de la ecuación 4 se calcula la proporción municipal de separación conyugal para cada nivel educativo, mediante:

$$
S C \_34 m_{u n}^{a j u s t}=S C \_34 m u n_{c e n s o}^{\text {esc }}+\text { Diferencia_SC_34 }{ }_{\text {depto_mun }}^{\text {esc }}
$$

Donde:

- $\quad S C \_34 m_{\text {esc }}^{a j u s t}=$ Proporción municipal ajustada de separación conyugal para nivel educativo esc.

- $\quad$ SC_34mun $n_{\text {censo }}^{\text {sc }}=$ Proporción municipal observada de separación conyugal en el Censo.

- Diferencia_SC_34 depto_mun $_{\text {esc }}=$ Diferencia entre la ENDS y el Censo, de la proporción de separación conyugal actual de las mujeres del grupo 30-34 años, del nivel educativo esc, en el departamento depto, correspondiente a dicho municipio.

Finalmente, para la estimación total del nivel de separación conyugal se aplica la distribución municipal del nivel educativo del municipio y obtenemos,

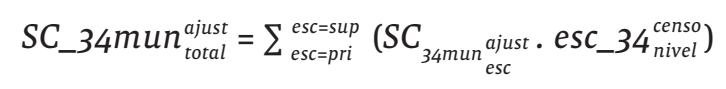

Donde:

- $S C_{34 m u n}^{\text {ajust }}$ total $=$ Proporción municipal ajustada de separación conyugal.

- $S C_{34 m u n}^{a j u s t}=$ Proporción municipal ajustada de separación conyugal para nivel educativo esc.

- $\quad$ esc_34 $4_{\text {nivel }}^{\text {censo }}=$ Proporción de mujeres del nivel educativo esc, en el municipio. 
Una restricción del modelo es la imposibilidad de ajustar la estimación de separación conyugal actual cuando el valor observado es cero. Dicha situación se observó en 3 de los 433 municipios de la muestra censal: Ituango en Antioquia, Tarqui/La Argentina en el Huila, y Mosquera/Olaya Herrera en Nariño, los cuales fueron excluidos de la estimación final a nivel municipal (únicamente disponible para 430 municipios).

Mediante la regresión se calcularon los coeficientes de los componentes de la ecuación 4 (ver Anexo 1) que permitieron estimar los niveles municipales ${ }^{10}$ de separación conyugal. En la Figura 1 se incluyen los resultados de los porcentajes observados (en el eje horizontal) en el Censo y las predicciones del modelo en el eje vertical, confirmando las mejoras que hace el método al incrementar el porcentaje de la separación conyugal como una forma de corregir la subestimación del Censo. El modelo de regresión para predecir la diferencia entre los niveles departamentales de separación conyugal actual, obtuvo una correlación de 0,573 y una correlación al cuadrado de 0,567, lo cual indica un nivel adecuado de asociación.

\section{Resultados}

Los resultados de las estimaciones se presentan de acuerdo a los componentes de la sección metodológica.

\subsection{Hallazgos del primer componente: los niveles de separación conyugal entre 1951 y 2015}

De acuerdo a los dos tipos de indicadores calculados en el primer componente, en primer lugar, se incluyen los hallazgos de la medición transversal; y, posteriormente, la estimación

10 Con el fin de facilitar la comprensión espacial de los resultados municipales, el Anexo 2 se incluye un mapa con los municipios de la muestra del Censo de 2005, delimitado por sus departamentos. También se incluyen los países fronterizos.
Figura 1. Valores observados y valores ajustados de la separación conyugal actual, según los municipios de la muestra censal. Colombia, 2005

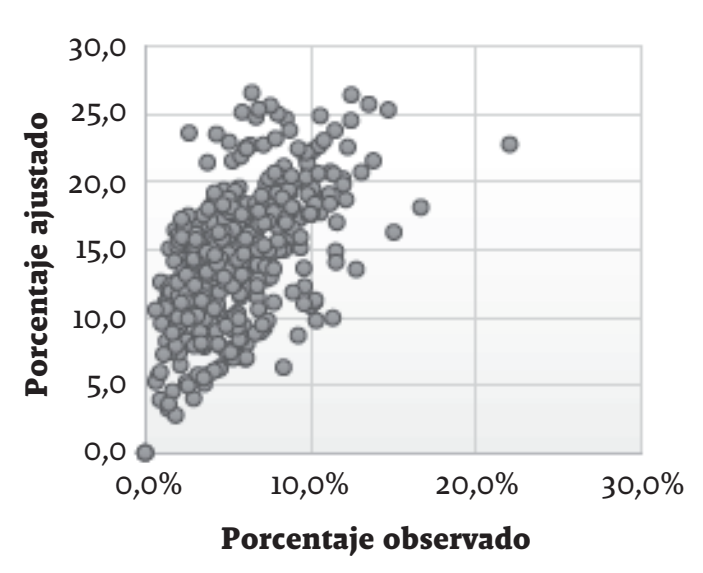

Fuente: elaboración propia a partir del Censo y la ENDS de 2005.

longitudinal resultante de la aplicación del método indirecto descrito en la metodología.

\subsubsection{Los niveles de separación conyugal actual, 1951-2015}

Los resultados de las estimaciones nos permiten contar con la radiografía de la separación conyugal, la cual confirma su aumento progresivo desde la segunda mitad del siglo XX, en cuanto un estado auto-declarado en un momento particular de tiempo. Tomando como referencia el grupo de mujeres de 30 a 34 años, dicho incremento se observa tanto en los censos de población como en las encuestas de fecundidad, demografía y salud (ver Tabla 4). En 1951 la primera de estas fuentes reportaba que $3 \%$ de las mujeres se declaraban como separadas; y en 2005 este valor, que además incluía a las divorciadas, llegó al 7\%. En el caso de la segunda fuente también se constata el aumento del porcentaje de separación o divorcio, al pasar del 9\% identificado en la ENF de 1976 al 16\% encontrado en la ENDS de 2015.

En el Censo el nivel se mantuvo entre $2 \%$ y $3 \%$ antes de 1985 . A partir de entonces, y cuando ya habían transcurrido nueve años desde la 
aprobación del divorcio vincular en 1976, dichos porcentajes han oscilado entre el $7 \%$ y el $8 \%$. Al considerar la serie de la ENF y las ENDS, se observa un salto importante desde la encuesta de 1990 , cuando se pasó de un nivel de $8 \%$ a uno de $14 \%$ respecto la versión anterior de 1986. Entre 1990 y 2015 los valores permanecieron alrededor de 14-16\%, a excepción de 2010 cuando llegó al 17\% y constituyó el nivel más alto en todo el periodo de análisis.

Cuando se toman los dos años de mayor coincidencia en las fechas del Censo y de la ENDS, llama la atención que las diferencias entre las proporciones estimadas por una u otra fuente son más grandes en el censo de 2005. Mientras en 198586 la ENDS reporta un punto porcentual adicional en el nivel de separación conyugal ( $8 \%$ vs $7 \%$ ), en 2005 esta brecha es de 9 puntos (16\% de la ENDS vs $7 \%$ del censo). Al contrastarlo con las proporciones de los otros estados civiles se observa que en 198586 los valores son similares en todos ellos, pero en 2005 las diferencias también son considerables en el estado de soltería, pues el Censo lo calcula en $23 \%$ y para la ENDS el porcentaje de mujeres nunca unidas era del $16 \%$.

Teniendo en cuenta que, para el 2005, los valores de la categoría "en unión" son iguales en ambas fuentes (67\%), y la viudez, aunque no es exactamente igual, tiene una participación minoritaria ( $1 \%-2 \%$ ), es posible afirmar que el bajo nivel de separación conyugal declarado en el Censo se origina en la sobrestimación de la soltería; y que este exceso se ha intensificado a partir de 1985, posiblemente como resultado de la preferencia por la categoría "soltera", que manifiestan algunas mujeres con uniones conyugales disueltas.

Una forma de aproximarnos al grupo de "solteras", provenientes del segmento de mujeres con uniones disueltas, es a través de la variable del número de hijos, tal como fue propuesto por Esteve et al. (2010). La estrategia se basa en el

Tabla 4. Evolución del estado civil y conyugal actual de las mujeres del grupo de edad 30-34, según los Censos de población, la ENF y la ENDS. Colombia 1951-2015

\begin{tabular}{|c|c|c|c|c|c|c|c|c|c|c|c|c|c|c|}
\hline \multirow{2}{*}{ Variable } & \multicolumn{6}{|c|}{ Censo } & \multirow{2}{*}{$\frac{\text { ENF }}{1976}$} & \multicolumn{7}{|c|}{ ENDS } \\
\hline & $1951^{*}$ & 1964 & 1973 & 1985 & 1993 & 2005 & & 1986 & 1990 & 1995 & 2000 & 2005 & 2010 & 2015 \\
\hline $\begin{array}{l}\text { Solteras/Nunca } \\
\text { unida }\end{array}$ & 264 & 20,7 & 19,2 & 17,7 & 18,7 & 22,6 & $11 / 4$ & 15,7 & 145 & 146 & 164 & 16,0 & 143 & 16 \\
\hline Sin hijo(s) & 0,0 & 0,0 & 7,0 & 7,8 & 6,6 & 10,5 & 7,9 & 9,9 & 9,3 & 10,3 & 10,7 & 9,2 & 8, & 8,5 \\
\hline Con hijo(s) & 0,0 & 0,0 & 7,7 & 6,2 & 7,0 & 11,9 & 3,5 & 5,8 & 5,2 & 43 & 5,7 & 6,8 & 6,2 & 7,6 \\
\hline Desconocido & 0,0 & 0,0 & 45 & 3,7 & 5,1 & 0,2 & 0,0 & 0,0 & 0,0 & 0,0 & 0,0 & 0,0 & 0,0 & 0,0 \\
\hline En unión & 67,5 & 747 & 74,5 & 73,1 & ال, & 67,0 & 78,6 & 73,9 & 69,9 & 70,3 & 67,3 & 66,5 & 67,6 & 66,5 \\
\hline $\begin{array}{l}\text { Separadas/ } \\
\text { Divorciadas }\end{array}$ & 2,7 & 2,0 & 3,1 & 6,9 & 7,7 & إ, & 8,7 & 8, 1 & 13,7 & 13,7 & 148 & 15,8 & 16,7 & 16,3 \\
\hline Viudas & 3,5 & 2,5 & 2,3 & 1,9 & 2,0 & 1,3 & 1,3 & 2,3 & 2,0 & 1,5 & 1,6 & 1,8 & $1 / 4$ & 1,2 \\
\hline Desconocido & 0,0 & 0,0 & 0,8 & 0,5 & 0,5 & 1,9 & 0,0 & 0,0 & 0,0 & 0,0 & 0,0 & 0,0 & 0,0 & 0,0 \\
\hline Total & 100,0 & 100,0 & 100,0 & 100,0 & 100,0 & 100,0 & 100,0 & 100,0 & 100,0 & 100,0 & 100,0 & 100,0 & 100,0 & 100,0 \\
\hline$N$ & 337311 & 529800 & 568050 & 953012 & 1360860 & 1504995 & 599 & 723 & 1296 & 1631 & 1626 & 5198 & 6740 & 5076 \\
\hline
\end{tabular}

Nota: proporción estimada a partir de los cuadros 14 (pp. 60-61) del Censo de 1951 (DANE, 1954).

Fuente: elaboración propia a partir de los Censos 1951-2005 (Minnesota Population Center, 2018), la ENF de 1976 (OPR, 2017) y las ENDS1986- 2015 (ICF, 1986-2015). 
postulado de que es muy probable que una mujer con algún hijo, y declarada como soltera en el Censo, lo(s) haya(n) tenido en el marco de alguna experiencia conyugal, ya sea en un matrimonio o en una unión libre. Dicho recurso metodológico tiene aún más sentido en los censos posteriores a 1985 que, como se mencionó, presentan mayores diferencias en la estimación de la soltería y de la separación/divorcio de la ENDS.

Al sumar la proporción de mujeres solteras con hijos al de separadas o divorciadas se obtiene un nivel de disolución de 15\% en el Censo de 1993. Comparándolo con la ENDS más cercana (en este caso la de 1995) se obtiene un resultado muy cercano al que da esta fuente de dicho estado conyugal (14\%). Al hacer lo mismo con el Censo de 2005 el nivel llega al 19\%, siendo 3 puntos porcentuales más alto al reportado por la ENDS del mismo año. A pesar de no ser un valor preciso, sí es una estimación más cercana en comparación con una medición que únicamente considere la proporción de "separadas o divorciadas" del censo ( $7 \%$ para 2005). Justamente la identificación de las brechas, en la estimación de los distintos estados civiles, es uno de los beneficios de trabajar simultáneamente con los censos y con las ENDS. Ahora bien, tales diferencias no son iguales en todos los grupos sociales, razón por la que debemos observar las brechas, entre las dos fuentes, de acuerdo al nivel educativo y la región de residencia.

Sin embargo, los departamentos muestran variaciones considerables, posibles de estimar con la ENDS, dada la representatividad que tienen a esta escala. La Figura 2 presenta el porcentaje departamental de separación conyugal actual de las mujeres entre 30 y 34 años, a partir de las dos fuentes comparadas. La línea negra corresponde a la estimación de la ENDS y la gris al Censo. Tal como se aprecia, la ENDS reporta mayores niveles que el Censo en todos los departamentos, aunque tales diferencias son más o menos grandes en función del departamento. Existen territorios en donde estas diferencias son pequeñas, como en el Quindío o en el Atlántico, en los que la brecha solo es de 0,8 y 1,5 puntos porcentuales, respectivamente. Por el contrario, en otros departamentos las diferencias son muy grandes, como sucede en San Andrés, el conjunto de Amazonas-Guaviare-Vaupés-Vichada-Guanía, Chocó y Bolívar, en donde las diferencias son de 21, 19, 17 y 16 puntos porcentuales, respectivamente.

\subsubsection{Los niveles de separación conyugal actual experimentada alguna vez, 1976- 2015}

Los resultados indican que, a diferencia de la medición transversal, la separación conyugal como un evento experimentado -al menos una vez en la vida- es más alta a lo largo del periodo de observación (1976-2015). En la Figura 3 se comparan los dos tipos de mediciones. La línea gris corresponde al porcentaje de mujeres de 30 a 34 años que en el momento de la encuesta se declaraban como separadas o divorciadas. La línea negra indica el porcentaje de mujeres que, sin importar el estado conyugal en cada año, habían experimentado una ruptura conyugal. En términos de la tendencia temporal, de la diferencia de ambas mediciones, se observa que el patrón fue similar hasta 1990, es decir, hubo una leve caída en 1986 con respecto a 1976 para -posteriormentevolver a incrementarse en 1990. A partir de allí se encuentra que, mientras la separación actual se mantuvo relativamente estable con valores entre $14 \%$ y $16 \%$, la acontecida alguna vez en la vida ha venido progresando constantemente hasta llegar a un nivel de 34\% en 2015; es decir, más del doble de lo que indicaron las mujeres cuando se les preguntó por su condición de separadas en el momento de la encuesta.

Cuando se tiene en cuenta la evolución de los otros estados conyugales, se observa que la diferencia entre la medición de la separación de corte transversal y la de corte biográfica se relaciona con la interferencia que las segundas o posteriores uniones tienen en la declaración del estado civil "actualmente unida". En efecto, con la aplicación del método indirecto también se obtiene el porcentaje de mujeres que no se habían separado de sus parejas, (Tabla 5, parte inferior del cuadro). Así, entre el total de mujeres que se declaraban como unidas en el momento de la encuesta, se puede establecer si dicha unión era 
Figura 2. Porcentaje de separación conyugal actual reportado en el Censo y la ENDS, de acuerdo al departamento de residencia. Mujeres 30-34. Colombia 2005

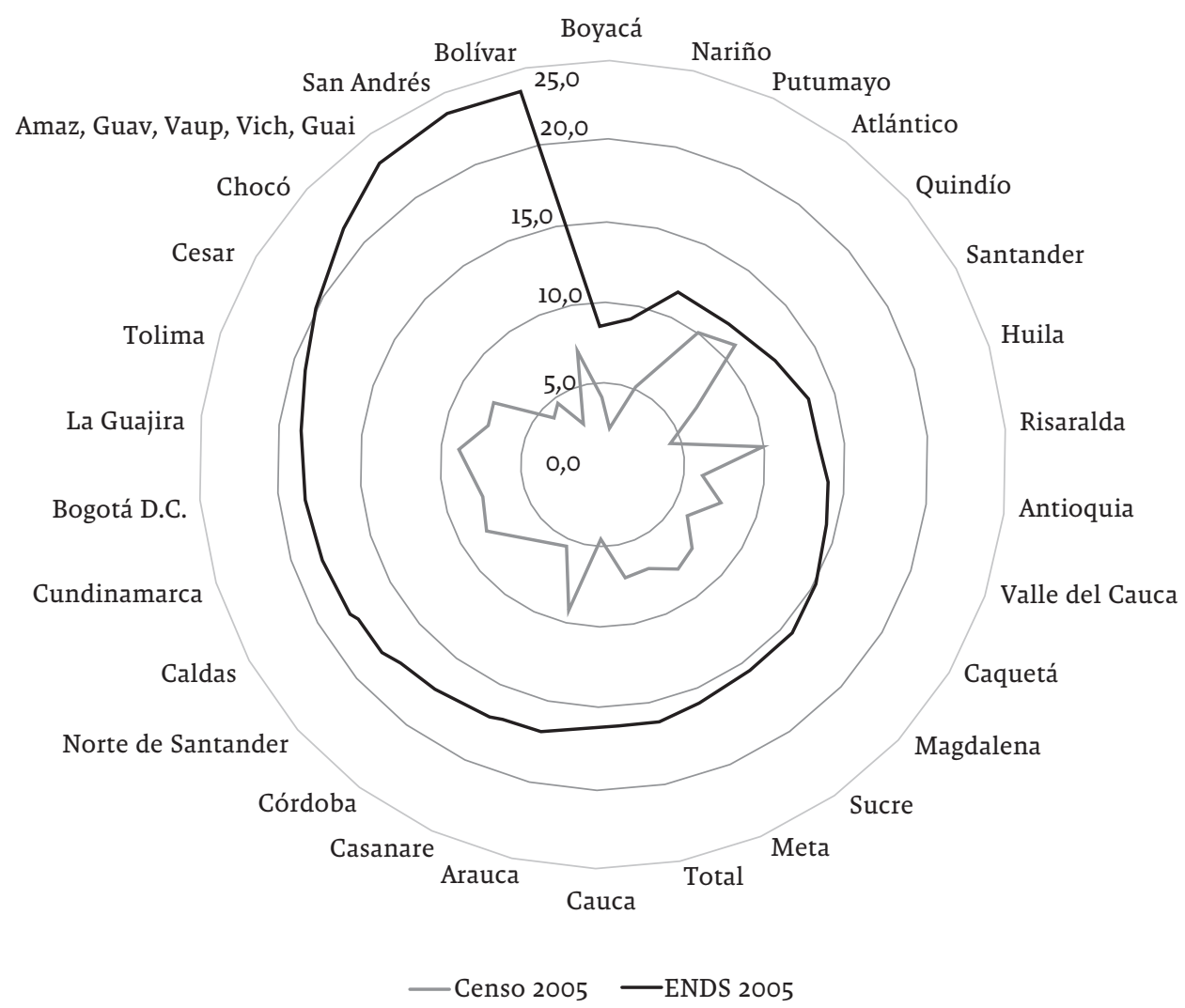

Fuente: elaboración propia a partir del Censo de 2005 (Minnesota Population Center, 2018) y la ENDS 2005 (Profamilia, Ministerio de Salud y Protección Social, e ICF, 2017b).

Figura 3. Nivel de separación conyugal actual y experimentado alguna vez en la vida. ENF 1976-ENDS 2015. Mujeres 30-34 años

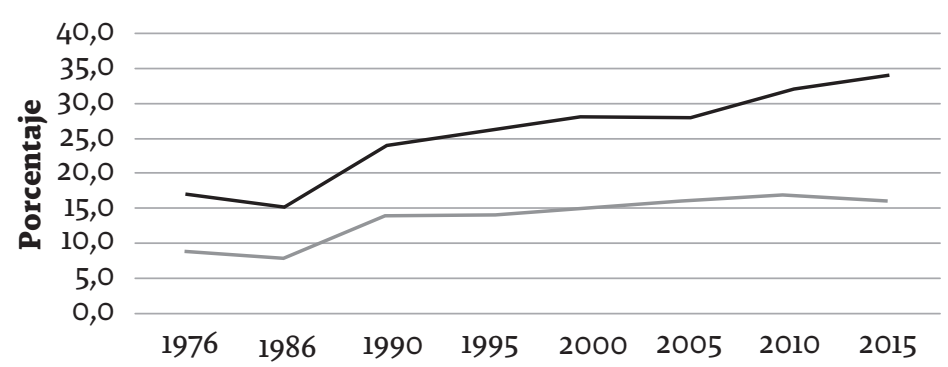

Año

$$
\text { — Separada actualmente - Alguna vez separada }
$$

Fuente: elaboración propia a partir de la ENF de 1976 (OPR, 2017) y la ENDS 1986-2015 (ICF, 1986-2015) 
la primera o si, por el contrario, era una segunda o posterior unión. En la Figura 4 se visualiza cómo el aumento de la separación conyugal (línea negra) se corresponde con un incremento de las segundas o posteriores uniones, entre el total de mujeres unidas en cada encuesta.

Así como la soltería se asocia al subregistro de la separación conyugal actual, las segundas o posteriores uniones se vinculan con el subregistro de la separación experimentada alguna vez en la vida. Esta afirmación se sustenta en el trabajo de revisión de las preguntas de la ENDS, presentado en la sección 2.2; el cual ha mostrado las ventajas del uso comparativo, por un lado, de los censos y las ENDS como fuentes fundamentales para el estudio de la nupcialidad en Colombia, y, por otro, de los estados civiles o conyugales que están íntimamente conectados.

\subsection{Hallazgos del segundo componente: los niveles municipales de separación conyugal actual, a partir del Censo de 2005}

De acuerdo con el ajuste de la estimación municipal, a partir de la información del estado civil de las mujeres entre 30-34 años, se observa que, de los 430 municipios para los cuales la muestra del Censo de 2005 dispone de información, 35,8\% reportan niveles de separación conyugal actual entre $15 \%$ y $19 \%$. Así mismo, en el 34,1\% de los territorios los valores son de $10 \%$ al $14 \%$; y en el $17,2 \%$ de las unidades,

Tabla 5. Distribución del estado conyugal actual y experimentado alguna vez.

Mujeres 30-34 años. Colombia 1976-2015

\begin{tabular}{|c|c|c|c|c|c|c|c|c|}
\hline \multirow{2}{*}{ Estado } & \multirow{2}{*}{$\begin{array}{c}\text { ENF } \\
1976\end{array}$} & \multicolumn{7}{|c|}{ ENDS } \\
\hline & & 1986 & 1990 & 1995 & 2000 & 2005 & 2010 & 2015 \\
\hline \multicolumn{9}{|c|}{ Estado actual } \\
\hline Solteras/Nunca unida & 11,0 & 16,0 & 14,0 & 15,0 & 16,0 & 16,0 & 14,0 & 16,0 \\
\hline En unión & 79,0 & 74,0 & 70,0 & 70,0 & 67,0 & 67,0 & 68,0 & 66,0 \\
\hline Separadas/Divorciadas & 9,0 & 8,0 & 14,0 & 14,0 & 15,0 & 16,0 & 17,0 & 16,0 \\
\hline Viudas & 1,0 & 2,0 & 2,0 & 1,0 & 2,0 & 2,0 & 1,0 & 1,0 \\
\hline Total & 100,0 & 100,0 & 100,0 & 100,0 & 100,0 & 100,0 & 100,0 & 100,0 \\
\hline \multicolumn{9}{|c|}{ Estado experimentado alguna vez } \\
\hline Solteras/Nunca unida & 11,0 & 15,0 & 14,0 & 14,0 & 16,0 & 16,0 & 14,0 & 16,0 \\
\hline $\begin{array}{l}\text { En unión sin experiencia de } \\
\text { disolución }\end{array}$ & 70,0 & 67,0 & 60,0 & 58,0 & 54,0 & 54,0 & 52,0 & 48,0 \\
\hline Alguna vez separada/divorciada & 17,0 & 15,0 & 24,0 & 26,0 & 28,0 & 28,0 & 32,0 & 34,0 \\
\hline Alguna vez viuda & 2,0 & 3,0 & 2,0 & 2,0 & 2,0 & 2,0 & 2,0 & 2,0 \\
\hline Total & 100,0 & 100,0 & 100,0 & 100,0 & 100,0 & 100,0 & 100,0 & 100,0 \\
\hline$N$ & 599 & 723 & 1296 & 1631 & 1626 & 5198 & 6740 & 5076 \\
\hline
\end{tabular}

Fuente: elaboración propia a partir de la ENF de 1976 (OPR, 2017) y la ENDS 1986-2015 (ICF, 1986-2015). 
Figura 4. Distribución porcentual del orden de la unión entre el grupo de mujeres actualmente unidas, y porcentaje de separación conyugal experimentado alguna vez en la vida. Mujeres 30-34. Colombia 1976-2015

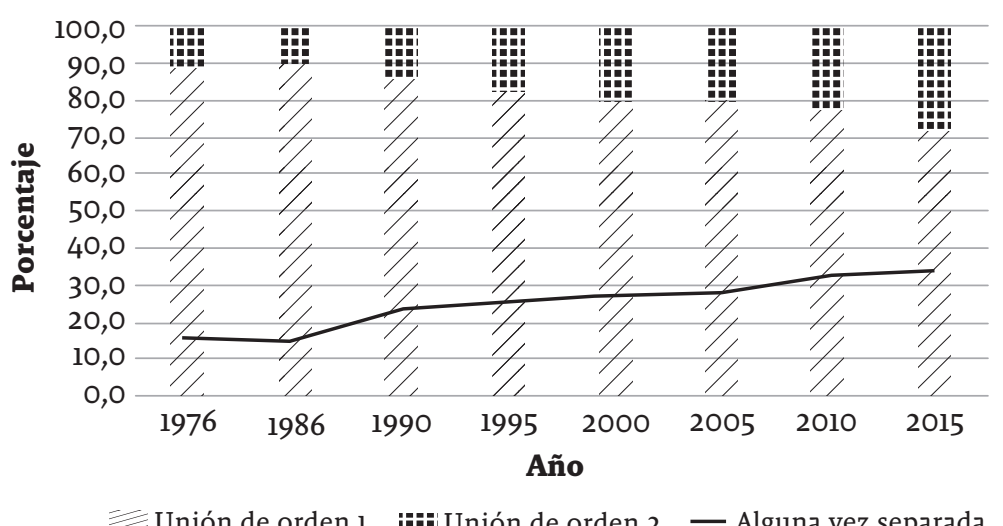

Fuente: elaboración propia a partir de la ENF de 1976 (OPR, 2017) y la ENDS 1986-2015 (ICF, 1986-2015).

entre $5 \%$ y $9 \%$. Adicionalmente, observamos que el 1,6\% de los municipios reportan niveles entre o y $4 \%$; y el $17,2 \%$ entre 5 y $9 \%$. En el grupo con valores entre $20 \%$ y $24 \%$, más elevados, se ubican 40 unidades territoriales $(9,2 \%$ sobre el total) y 8 de los 430 municipios ( $1,9 \%)$ en el rango más alto de separación conyugal: $25 \%$ o más.

En términos de las variaciones territoriales, la Figura 5 permite identificar las variaciones al interior de cada una de estas. En la región del Atlántico y del Pacífico o, como Virginia Gutiérrez de Pineda (1964) lo denominó en su estudio pionero sobre la familia colombiana, el complejo Fluvio-Minero ${ }^{11}$, de los 162 municipios

11 Los complejos culturales son definidos como "dimensiones patrias dotadas básicamente de un hábitat particular, dentro del cual un conjunto demográfico de características étnicas dadas, había creado mediante un proceso histórico vivido separadamente, la sociedad, representada en instituciones, dentro de las cuales operaban valores, imágenes y pautas de comportamiento en complicada acción integrativa y bajo marcada identidad" (Gutiérrez, 1964, p. XIII). Así, definió cuatro complejos culturales: a) el andino o americano, b) el santandereano o neohispánico, c) el de la Montaña o antioqueño, y d) el litoral-fluvio-minero o negroide. Entre los trabajos que emplean esta clasificación para analizar otras dinámicas familiares destaca el de Saavedra et al. (2013) para analizar las uniones consensuales a partir del Censo de 2005. de la muestra -correspondientes a las dos regiones- $56 \%$ tenían niveles de separación por encima del $14 \%$, mientras que en el conjunto de todos los municipios esto ocurrió en el $47 \%$, es decir, casi 10 puntos porcentuales menos. En el mismo sentido, Gutiérrez afirmaba que el complejo se caracterizaba por "una dinámica permanente de desintegración y reconstrucción de la célula doméstica" (Gutiérrez, 1964, p. XVI), vinculada a la presencia de diversas formas de unión libre, poliginia y relaciones esporádicas. Por su parte, la región Central -correspondiente a los complejos culturales Antioqueño y Andino de la propuesta de Gutiérrez de Pinedaentre sus 135 municipios de la muestra, 37\% reportan niveles de separación por encima del 14\%, generando una diferencia de 20 puntos porcentuales por debajo del complejo Fluvial-Minero.

Gracias al mejoramiento de los censos y a la disponibilidad de otras encuestas, como la ENDS, la investigación sociodemográfica puede señalar las variaciones al interior de cada complejo cultural propuesto por Virginia Gutiérrez de Pineda. Así, por ejemplo, aunque los complejos Antioqueño y Andino exhibían los niveles más altos de institucionalización 
de las uniones por medio del matrimonio -en un contexto en donde la religión alcanzaba su plenitud máxima "como posición en la sociedad y proyección ética sobre el individuo y la estructuración familiar" (Gutiérrez, 1964, p. XV)-, municipios como La Dorada, Victoria, Villamaría, y Anserma en el departamento de Caldas, mostraban niveles de separación conyugal actual por encima del $20 \%$, a partir de las estimaciones ajustadas del Censo de 2005. Sin embargo, esta misma región también incluye territorios con muy bajos niveles del fenómeno. De los 7 municipios con porcentajes inferiores al $5 \%$ de separación conyugal, 3 se encuentran en la región Central, en particular, en el departamento de Antioquia: Arboletes-San Juan de Urabá (con 2,8\%), San Pedro de UrabáTurbo-Necoclí (3,3\%), y Caucasia-Nechí $(4,0 \%)^{12}$.

Por otra parte, la Figura 5 muestra el nivel de separación en la región de la Orinoquía/ Amazonía, la cual no fue incluida en el estudio de Gutiérrez de Pineda por ser una región extensa de difícil acceso, por su geografía selvática y por estar muchos años incomunicada con el país. A partir del Censo de 2005, y mediante el ajuste aquí presentado, es posible saber que, por ejemplo, de sus 14 municipios incluidos en la muestra censal, 9 de ellos tenían valores superiores del $14 \%$. Estos territorios coinciden en ser departamentos con un alto porcentaje de población indígena, como los casos de Guainía, Vaupés, Amazonas, Vichada y Putumayo, en donde $62 \%, 58 \%, 41 \%, 40 \%$ y $19 \%$ de su población se reconoce como tal, respectivamente (DANE, 2018).

Desde la formulación misma de los complejos culturales, Gutiérrez de Pineda señala la dificultad de dotarlos de una definición unívoca y excluyente que delimite, geográficamente, una realidad tan compleja como las dinámicas familiares observadas en el territorio. Uno de estos ejes de diferenciación es la estratificación social, pues, como ella misma lo dice: "lo que en un complejo cultural dado es

12 Los resultados de las estimaciones puntuales para todos los municipios de la muestra están disponibles por correo electrónico. verdadero dentro de una de sus clases sociales, no lo es en otra, y generalmente cada una acusa rasgos identificatorios diferentes u opuestos" (Gutiérrez, 1964, p. XVII). A pesar de ello, el trabajo etnográfico, histórico y demográfico realizado por la autora, es una contribución fundamental para entender las variaciones regionales de la familia en Colombia. Una reflexión explicativa de tales diferencias supera los alcances del presente trabajo, y constituyen en sí mismas un tema de investigación futuro.

\section{Conclusiones}

La revisión de la literatura sobre la separación conyugal (Ruiz-Vallejo, 2018) ha permitido identificar la ausencia de mediciones recientes sobre la separación conyugal en Colombia, posteriores al estudio de Zamudio y Rubiano (1991). Desde entonces, han pasado más de tres décadas en que la sociedad colombiana ha avanzado en su transición demográfica (Profamilia y Ministerio de Salud y Protección Social, 2017). La escasez de fuentes de datos biográficas a lo largo de este periodo ha impedido contar con estimaciones recientes que, de forma directa, documenten dichos cambios. Sin embargo, en ese mismo periodo se cuenta con siete Encuestas de Demografía y Salud (o $D H S$ por sus siglas en inglés) que, por un lado, permiten una estimación indirecta de la intensidad de la disolución de las uniones en ese periodo y, por otro, pueden usarse de forma complementaria con el Censo de 2005, con el fin de tener estimaciones municipales del fenómeno.

El análisis detallado de las preguntas por el estado civil de los Censos de población identifica el conteo de 1951 como el primer censo que incluyó el estado "separado/a o divorciado/a" en sus estimaciones. Sin embargo, al no incluir el orden del estado civil declarado, dicha fuente subregistra la intensidad de la separación. Tomando el grupo de mujeres de 30 a 34 años, los resultados mostraron cómo, entre 1951 y 1973, el porcentaje de mujeres separadas estuvo en el rango $2-3 \%$ y, entre 1985 y 2005 , alrededor del $7 \%$. Cuando tales niveles se comparan con las estimaciones de la DHS, en donde la estimación 


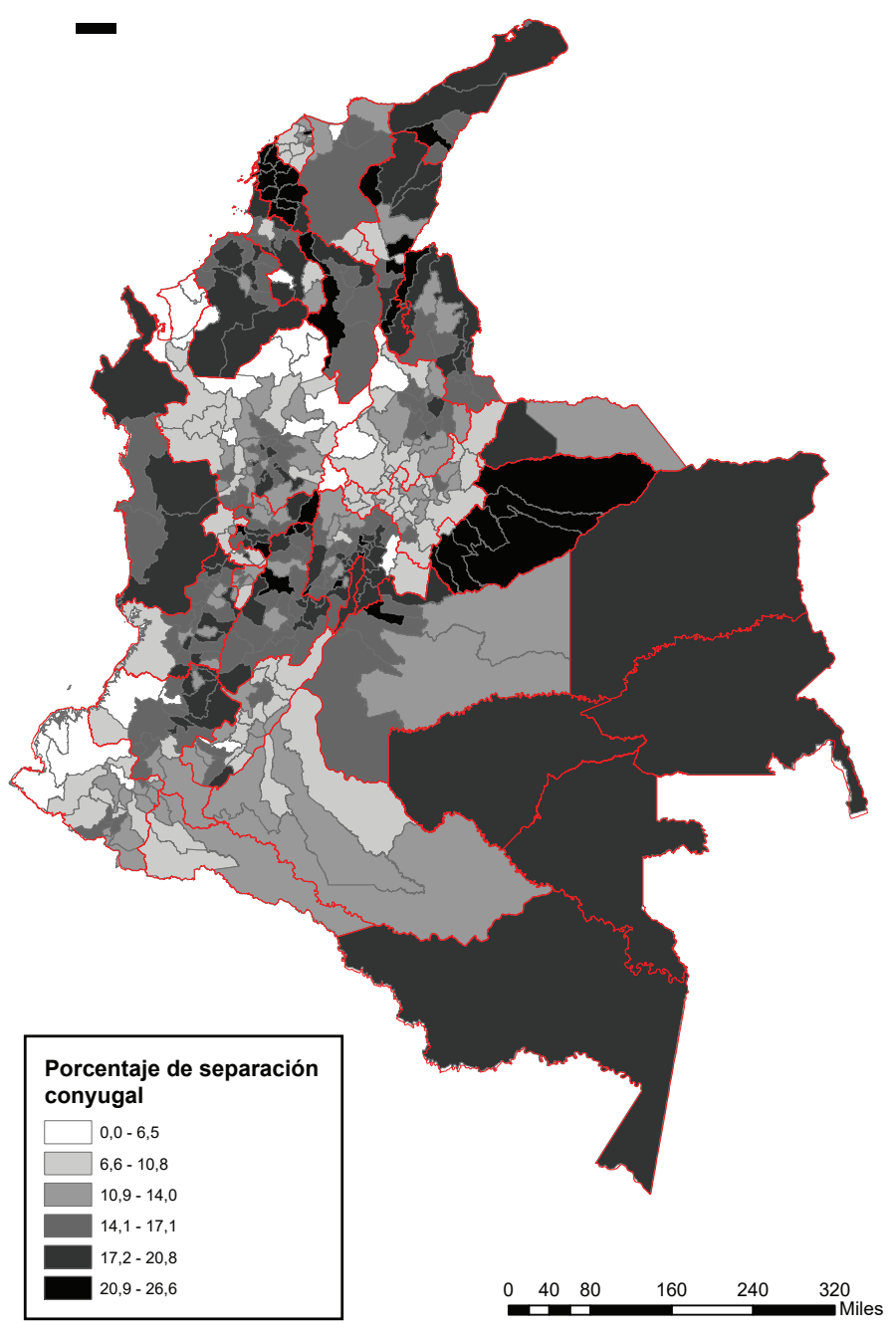

Fuente: elaboración propia a partir del Censo 2005 (Minnesota Population Center, 2018) y la ENDS 2005 (Profamilia, Ministerio de Salud y Protección Social, e ICF, 2017b).

de la soltería es más precisa por circunscribirse únicamente a las mujeres "nunca unidas", se observa que los niveles son más elevados: entre 13 y 16\% entre 1990 y 2015.

El subregistro de la separación conyugal en un momento específico del tiempo, por parte del Censo, obedece a la sobreestimación de la soltería -dada la preferencia de las mujeres por dicho estado- tras la finalización de una unión conyugal. En ese sentido, se recomienda que la pregunta por 
el estado civil en el Censo de población incluya una pregunta sobre el orden de las uniones. Esto para quienes reportan dicha condición (si es la primera, segunda, etc.), y que se garantice que las personas solteras sean, en realidad, las "nunca unidas". De tal manera se mejorarían las estimaciones a partir de dicha fuente.

Tomando el Censo y la DHS de 2005 se constató que esta diferencia varía de acuerdo al nivel educativo y la región de residencia, siendo mayor en los grupos intermedios de escolaridad y en las regiones de Bogotá y Orinoquía/Amazonía. Pese al mejoramiento del cálculo por parte de la $D H S$, esta medición tampoco considera el orden de la disolución, es decir, no incluye la disolución de las personas que se encontraban en una segunda o posterior unión, en el momento de la encuesta. Por tanto, la estimación del porcentaje de mujeres "actualmente" separadas o divorciadas, no da cuenta de la intensidad real de haber disuelto la primera unión.

Mediante la aplicación de un método de estimación indirecto (Clark y Brauner-Otto, 2015) se calculó la intensidad de la separación conyugal, encontrando que esta ha venido en ascenso continuo, desde 1986, hasta llegar a un nivel de $34 \%$ en 2015, es decir, 2 de cada 3 mujeres alguna vez unidas -del grupo de edad 30-34disolvían su primera unión. Este valor es más del doble de la separación conyugal declarada al momento de la encuesta. Nuevamente se encontraron brechas importantes, pues las diferencias son más grandes en los grupos de baja escolaridad y en las regiones de la Orinoquía/ Amazonía y en la Atlántica. El método indirecto es efectivo, pues sus estimaciones fueron muy cercanas a las obtenidas, de forma directa, mediante las historias de unión de la ENF de
1976 y de la DHS de 2015. A pesar de su eficacia, valdría la pena que, en caso de no incluir el módulo de historias de uniones en las versiones posteriores, al menos se incluya la fecha de la primera disolución. De tal manera, se podrían ofrecer estimaciones directas de la separación conyugal.

Los hallazgos del estudio confirman el aumento de la separación, en calidad de una experiencia vivida alguna vez en la vida, y en calidad de un estado conyugal específico en un momento determinado. Teniendo en cuenta el último indicador, la investigación identificó variaciones importantes en los municipios colombianos. Dichas mediciones son posibles de obtener únicamente con el Censo, gracias a su nivel de desagregación territorial. Así, el presente estudio propuso un método para la corrección del subregistro de la separación conyugal actual, haciendo que, por primera vez, se obtengan datos del fenómeno a una escala municipal.

Al concebirse como una aportación meramente metodológica, centrada en la estimación de la separación conyugal; en esta investigación no se formularon ni probaron hipótesis que explicaran el aumento de dicho fenómeno. En ese sentido se recomienda que, en futuros trabajos, se investiguen los factores o diferenciales que explican las variaciones territoriales de la separación conyugal. Esto a partir de otras variables del contexto socioeconómico que también han presentado cambios desde la segunda mitad del siglo $\mathrm{XX}$ como, por ejemplo, el incremento de la participación laboral y educativa de las mujeres, la visibilización de formas no convencionales de familia, o las distintas expresiones que tuvo el conflicto armado en los territorios. 
Fernando Ruiz-Vallejo

\section{Anexos}

Anexo 1. Resultados de la regresión para la estimación de los coeficientes del método de ajuste. Colombia, 2005

\begin{tabular}{|c|c|c|c|}
\hline Tipo de parámetro & Parámetro & Coeficiente & Sig \\
\hline \multirow{28}{*}{ Territorial } & Antioquia & $-0,173$ & 0,013 \\
\hline & Atlántico & $-0,206$ & 0,002 \\
\hline & Bogotá & $-0,092$ & 0,129 \\
\hline & Bolívar & $-0,037$ & 0,553 \\
\hline & Boyacá & $-0,176$ & 0,015 \\
\hline & Caldas & $-0,127$ & 0,065 \\
\hline & Caquetá & $-0,124$ & 0,044 \\
\hline & Cauca & $-0,086$ & 0,159 \\
\hline & Cesar & $-0,078$ & 0,206 \\
\hline & Córdoba & $-0,069$ & 0,252 \\
\hline & Cundinamarca & $-0,104$ & 0,108 \\
\hline & Huila & $-0,165$ & 0,024 \\
\hline & La Guajira & $-0,081$ & 0,151 \\
\hline & Magdalena & $-0,134$ & 0,037 \\
\hline & Meta & $-0,097$ & 0,128 \\
\hline & Nariño & $-0,151$ & 0,025 \\
\hline & Norte de Santander & $-0,103$ & 0,112 \\
\hline & Quindío & $-0,195$ & 0,002 \\
\hline & Risaralda & $-0,210$ & 0,002 \\
\hline & Santander & $-0,164$ & 0,019 \\
\hline & Sucre & $-0,118$ & 0,064 \\
\hline & Tolima & $-0,086$ & 0,174 \\
\hline & Valle & $-0,128$ & 0,036 \\
\hline & Arauca & $-0,133$ & 0,032 \\
\hline & Casanare & $-0,027$ & 0,672 \\
\hline & Putumayo & $-0,139$ & 0,020 \\
\hline & San Andrés & 0,037 & 0,556 \\
\hline & Amazonas, Guaviare, Vaupés, Vichada, Guainía & 0,007 & 0,900 \\
\hline \multirow{2}{*}{ Escolaridad } & Secundaria & $-0,016$ & 0,445 \\
\hline & Superior & $-0,096$ & 0,018 \\
\hline \multirow{2}{*}{ Unión } & Personas unidas & $-0,015$ & 0,929 \\
\hline & Unión libre sobre total de uniones & $-0,175$ & 0,058 \\
\hline Constante & &, 350 & 021 \\
\hline
\end{tabular}

Fuente: elaboración propia a partir del Censo 2005 (Minnesota Population Center, 2018) y la ENDS 2005 (Profamilia, Ministerio de Salud y Protección Social, e ICF, 2017b). 


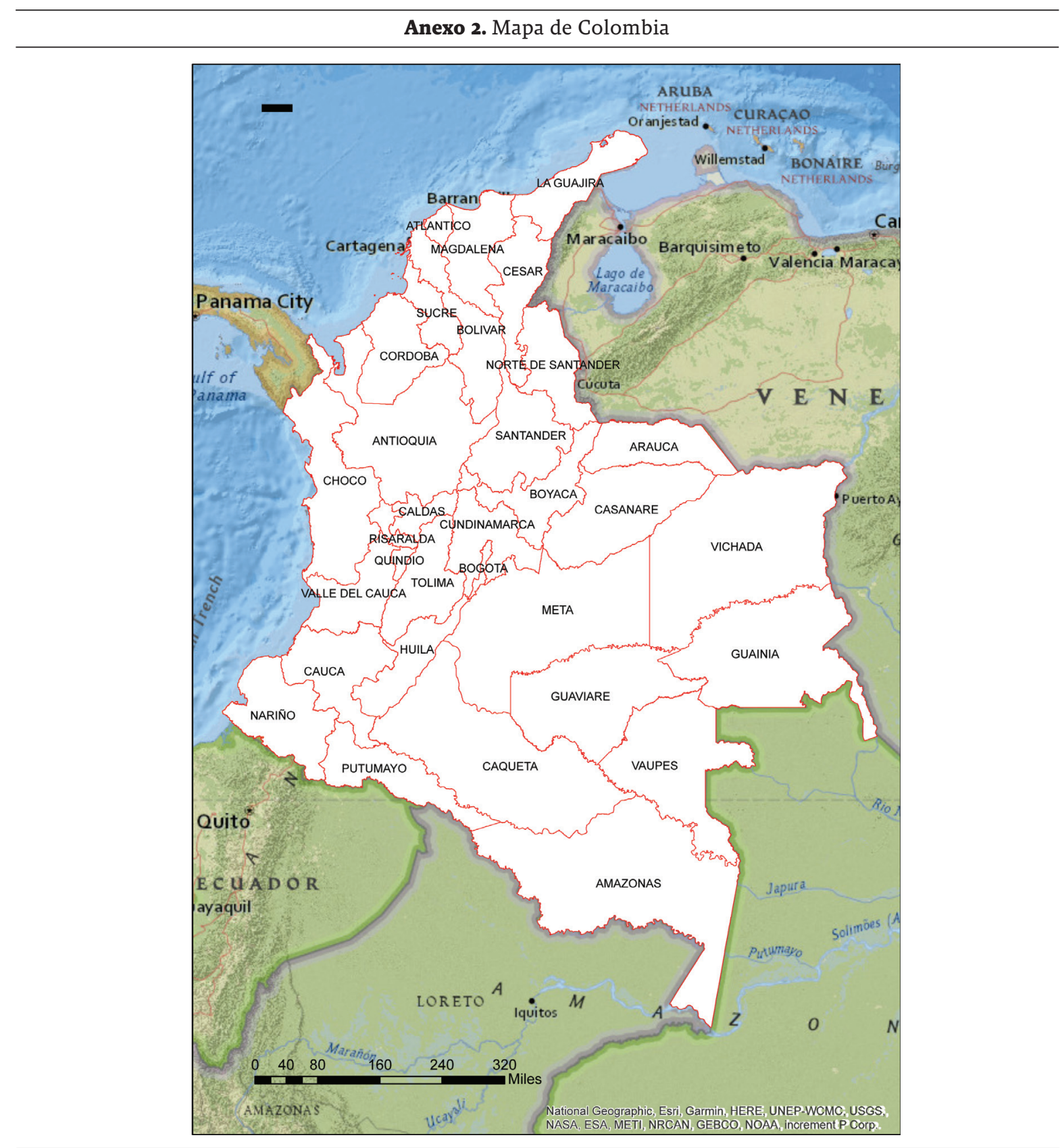

Nota: la región Atlántica está conformada por 8 departamentos (Atlántico, Bolívar, Guajira, Cesar, Córdoba, Magdalena, San Andrés y Sucre); la Oriental por 5 (Cundinamarca, Meta, Norte de Santander y Santander); la Central por 7 (Antioquia, Caldas, Caquetá, Huila, Quindío, Risaralda y Tolima); la Pacífica por 4 (Cauca, Chocó, Nariño y Valle del Cauca); la Orinoquía y Amazonía por 8 (Amazonas, Arauca, Casanare, Guainía, Guaviare, Putumayo, Vaupés y Vichada) y Bogotá por ella misma.

Fuente: National Geographic Society y Esri (2009). 


\section{Referencias bibliográficas}

Abalos, J. B. (2017). Divorce and separation in the Philippines: Trends and correlates. Demographic Research, 36(1), 1515-1548. https://doi.org/10.4054/DemRes.2017.36.50

Binstock, G. (2004). Cambio en las pautas de formación y disolución de la familia entre las mujeres de la Ciudad de Buenos Aires. Revista Población de Buenos Aires, 1(0), 8-15.

Bucheli, M. y Vigna, A. (2005). Un estudio de los determinantes del divorcio en Uruguay. Desarrollo y Sociedad, 2005(01), 1-21. https://doi.org/10.13043/dys.56.1

Cabella, W. (1998). La evolución del divorcio en Uruguay (1950-1995). Notas de población, 67/68, 209-246.

Cabella, W. (2008). Dissolução e formação de novas uniões: uma análise demográfica das tendências recentes no Uruguai (No. 56). Recuperado de http://www.nepo.unicamp.br/publicacoes/textos_ nepo/textos_nepo_56.pdf

Cabella, W. (2010). Los determinantes de la ruptura de la primera unión en el Uruguay : un análisis a partir de dos encuestas retrospectivas. Revista Latinoamericana de Poblacion, 4(7), 31-56.

Cabella, W., Peri, A. y Street, M. C. (2005). Buenos Aires y Montevideo: ¿dos orillas y una transición? La segunda transición demográfica en perspectiva biográfica. En S. Torrado (Ed.), Trayectorias nupciales, familias ocultas (pp. 207-232). Buenos Aires, Argentina: CIEPP, Miño y Dávila.

Clark, S. y Brauner-Otto, S. (2015). Divorce in sub-Saharan Africa: Are Unions Becoming Less Stable? Population and Development Review, 41(4), 583-605. https://doi.org/10.1111/j.1728-4457.2015.00086.x

DANE -Departamento Administrativo Nacional de Estadística-. (1954). Censo de Población, 1951. Resumen. Bogotá, Colombia: DANE.

DANE -Departamento Administrativo Nacional de Estadística-. (1964). Censo de Población 1964. Manual de instrucciones para los empadronadores de los censos. Bogotá, Colombia: DANE.

DANE -Departamento Administrativo Nacional de Estadística-. (1973). Censo de Población 1973. Manual del recolector. Bogotá, Colombia: DANE.

DANE -Departamento Administrativo Nacional de Estadística-. (1985). Censo de Población 1985. Manual del empadronador de formulario ampliado. Bogotá, Colombia: DANE.

DANE -Departamento Administrativo Nacional de Estadística-. (1993). Censo de Población 1993. Instructivos para diligenciar los formularios. Bogotá, Colombia: DANE.

DANE -Departamento Administrativo Nacional de Estadística-. (2005). Manual Técnico Censo General 2005. Bogotá, Colombia: DANE. Recuperado de https://www.dane.gov.co/files/censos/ ManualTecnico.pdf

DANE -Departamento Administrativo Nacional de Estadística-. (2018). Sistema de Consulta del Censo de 2005. Recuperado de https://www.dane.gov.co/index.php/estadisticas-por-tema/ demografia-y-poblacion/censo-general-2005-1/sistema-de-consulta-censo-2005

Esteve, A., García, J. y Mccaa, R. (2010). La enumeración de la soltería femenina en los censos de población: Sesgo y propuesta de corrección. Papeles de Poblacion, 16(66), 9-40. 
La separación conyugal en los Censos y en las Encuestas de Demografía y Salud en Colombia, 1951-2015

Estrada, V. (2015). La valeur des chiffres: la production et les usages des statistiques démo-graphiques et de santé publique en Colombie1886-1947. París, Francia: Écoles des Hautes Études en Science Sociales.

Estrada, V. (2017). ¿Cuántos somos? Una historia de los censos civiles y de la organización estadística en Colombia en la primera mitad del siglo XX. Historia Crítica, (64), 141-160. https://doi.org/10.7440/ histcrit64.2017.08

Flórez, C. E. y Sánchez, L. M. (2013). Fecundidad y Familia en Colombia: ¿hacia una segunda transición demográfica?. Estudios a Profundidad basado en las Encuestas Nacionales de Demografía y Salud, ENDS 1990-2010. Serie. Bogotá, Colombia: Profamilia.

Fussell, E. y Palloni, A. (2004). Persistent Marriage Regimes in Changing Times. Journal of Marriage and Family, 66(5), 1201-1213. https://doi.org/10.1111/j.0022-2445.2004.00087.x

García, B. y Rojas, O. (2004). Las uniones conyugales en América Latina: transformaciones en un marco de desigualdad social y de género. Notas de población, 78, 65-96.

Goldman, N. (1981). Dissolution of First Unions in Colombia, Panama, and Peru. Demography, 18(4), 659-679.

Gutiérrez, V. (1964). Familia y cultura en Colombia (1975a ed.). Bogotá, Colombia: Instituto Colombiano de Cultura.

ICF. (1986-2015). Colombia Demographic and Health Surveys (1986, 1990, 1995, 2000, 2005, 2010, 2015) [Base de datos]. Financiado por USAID. Rockville, Maryland, Estados Unidos: ICF [Distribuidor]. Recuperado de https://dhsprogram.com/data/available-datasets.cfm

Masciadri, V. (2002). Tendencias recientes en la constitución y disolución de las uniones en Argentina. Notas de Población, 74, 53-110.

Masciadri, V. (2017). La nupcialidad en Buenos Aires a mediados del siglo XX: Chascomús, La Plata y San Martín. Papeles de Población, 23(92), 105-150. https://doi.org/10.22185/24487147.2017.92.015

Minnesota Population Center. (2018). Integrated Public Use Microdata Series, International: Version 7.0 [dataset]. Minneapolis, Estados Unidos: IPUMS.

National Geographic Society y Esri. (2019). Mapa Base de la National Geographic Society para Colombia. Recuperado de https://www.arcgis.com/home/item.html?id=eff94b7al7574e6b8d8c5cea63d71535

OPR -Office of Population Research of Princeton University-. (2017). World Fertility Survey. Colombia 1976 [Dataset]. New Jersey, Estados Unidos: Corporación Centro Regional de Población [Productor], OPR [Distribuidor]. Recuperado de https://opr.princeton.edu/archive/wfs/

Ojeda, N. (1986). La Separación y el Divorcio en México vistos desde la Perspectiva Demográfica. Estudios Demográficos y Desarrollo Urbano, 1(2), 227-265.

Ojeda, N. y González, E. (2008). Divorcio y separación conyugal en México en los albores del siglo XXI. Rev. Mex. Sociol, 70(1), 11l-145. https://doi.org/10.22201/iis.01882503p.2008.001.6120

Pérez, J. y Ojeda, N. (2016). Una nueva mirada a los factores predictivos de la disolución conyugal voluntaria en México. En M. L. Coubès, P. Solís y M. E. Zavala de Cosío (Eds.), Generaciones, cursos de vida y desigualdad social en México (pp. 223-254). Ciudad de México, México: El Colegio de México; El Colegio de la Frontera Norte. 
Profamilia, Ministerio de Salud y Protección Social e ICF. (2017a). Colombia Demographic and Health Survey 2015 [Base de datos]. TLIR71.DTA. Rockville, Maryland, Estados Unidos: Profamilia, Ministerio de Salud y Protección Social e ICF [Productores], ICF [Distribuidor]. Recuperado de https://dhsprogram.com/data/available-datasets.cfm

Profamilia, Ministerio de Salud y Protección Social e ICF. (2017b). Colombia Demographic and Health Survey 2005 [Base de datos]. TLIR71.DTA. Rockville, Maryland, Estados Unidos: Profamilia, Ministerio de Salud y Protección Social e ICF [Productores], ICF [Distribuidor]. Recuperado de https://dhsprogram.com/data/available-datasets.cfm

Profamilia y Ministerio de Salud y Protección Social. (2017). Encuesta Nacional de Demografía y Salud. ENDS 2015. Tomo I. Componente demográfico. Bogotá, Colombia: Profamilia-MSPS.

Quintín, P. (2008). Perspectivas sobre la conyugalidad. Una revisión bibliográfica. Documentos de Trabajo CIDSE. Cali, Colombia: Universidad del Valle.

República de Colombia. (2005). Ley 979 de 2005. Bogotá, Colombia: Congreso de la República. Recuperado de http://normatividad.sembello.gov.co/men/docs/pdf/ley_0979_2005.pdf

Ruiz-Vallejo, F. (2018). La separación conyugal en Colombia, 1951-2015: geografías y biografías en clave de género (tesis de doctorado). Universitat Autònoma de Barcelona, Barcelona, España.

Saavedra, A. C., Esteve, A. y López-Gay, A. (2013). La Union Libre en Colombia: 1976-2005. Revista Latinoamericana de Poblacion, 7(13), 107-127.

Sana, M. (2001). La segunda transición demográfica y el caso argentino. En Asociación de Estudios de Población de la Argentina (Ed.), V Jornadas Argentinas de Estudios de Población (pp. 65-79). Buenos Aires, Argentina: AEPA.

Solís, P. y Ferraris, S. (2014). Nuevo siglo, ¿nuevas pautas de formación y disolución de uniones? En C. Rabell (Ed.), Los mexicanos. Un balance del cambio demográfico (pp. 269-305). Ciudad de México, México: Fondo de Cultura Económica.

Vidales, L. (1978). Historia de la estadística en Colombia. Bogotá, Colombia: Banco de la República, Departamento Administrativo Nacional de Estadística.

Zamudio, L. y Rubiano, N. (1991). Las separaciones conyugales en Colombia. Bogotá, Colombia: Universidad Externado de Colombia. 